\title{
Revisão taxonômica de Leptolobium (Papilionoideae, Leguminosae)
}

Rodrigo Schütz Rodrigues ${ }^{1,3}$ e Ana Maria Goulart de Azevedo Tozzi²

Recebido em 15/09/2011. Aceito em 18/01/2012

\begin{abstract}
RESUMO
(Revisão taxonômica de Leptolobium (Papilionoideae, Leguminosae)). Este trabalho apresenta uma revisão taxonômica de Leptolobium Vogel, incluindo chave de identificação, descrições, ilustrações e mapas de distribuição dos táxons. Leptolobium, com 12 espécies aceitas, inclui árvores ou arbustos com flores de corola branca, actinomorfa a levemente zigomorfa, 10 estames livres, ovário estipitado multiovulado, legumes indeiscentes, samaroides ou nucoides, sementes compressas e eixo hipocótilo-radícula bulboso. Leptolobium é um gênero exclusivamente neotropical, ocorrendo desde o sul do México até o norte da Argentina. Onze espécies ocorrem no Brasil, sendo sete espécies endêmicas. O lectótipo de Sweetia glazioviana Harms é designado neste trabalho. Em adição, são apresentadas informações sobre usos, nomes populares, distribuição geográfica e habitats de cada espécie.
\end{abstract}

Palavras-chave: Fabaceae, Sophoreae, clado genistoide, taxonomia, Acosmium

\begin{abstract}
(A taxonomic revision of Leptolobium (Papilionoideae, Leguminosae)). This revision of Leptolobium Vogel includes an identification key, descriptions, illustrations, and distribution maps for the taxa. Leptolobium comprises 12 species, and is characterized by its arboreal or shrubby habit, flowers with white, actinomorphic or slightly zygomorphic corollas, 10 free stamens, a stipitate ovary with many ovules, indehiscent (samara-like or nut-like) fruits, compressed seeds, and a bulbose hypocotyl-radicle axis. Leptolobium is a neotropical genus that occurs from Mexico to northern Argentina. Eleven species are found in Brazil, seven of which are endemic to the country. The lectotype of Sweetia glazioviana Harms is designated in this paper. In addition, information about uses, common names, geographical distribution, and habitats are provided.
\end{abstract}

Key words: Fabaceae, Sophoreae, genistoid clade, taxonomy, Acosmium

\section{Introdução}

Leptolobium foi descrito por Vogel (1837), que organizou o gênero nas seções Leptolobium e Mesitis Vogel, com base na morfologia das folhas e do embrião. No entanto, Bentham (1865) considerou Leptolobium e o gênero Acosmium Schott, sinônimos de Sweetia Spreng. Mohlenbrock (1963) manteve a mesma circunscrição de Bentham (1865) em sua revisão de Sweetia, além de propor novos táxons. Yakovlev (1969), por sua vez, realizou outra revisão de Sweetia, considerando o gênero monospecífico. Neste trabalho, Yakovlev (1969) restabeleceu Acosmium como gênero distinto por apresentar todas as pétalas semelhantes e frutos com uma ala estreita. Na circunscrição de Yakovlev (1969), Acosmium foi organizado nas seções Acosmium, Leptolobium (Vogel) Yakovlev, Mesitis (Vogel) Yakovlev e Praeclara Yakovlev.
Estudos taxonômicos, incluindo morfologia de plântulas (Rodrigues \& Tozzi 2008a), bem como uma análise cladística (Rodrigues \& Tozzi 2007a), evidenciaram que Acosmium, como circunscrito por Yakovlev (1969), não corresponderia a um gênero monofilético. Desta forma, Rodrigues \& Tozzi (2007a) propuseram que Acosmium deveria ficar restrito aos táxons da seção Acosmium (Rodrigues \& Tozzi 2009). Eles restabeleceram o gênero Leptolobium (Rodrigues \& Tozzi 2008b), incluindo as seções Leptolobium e Mesitis e descreveram o gênero Guianodendron Sch. Rodr. \& A.M.G. Azevedo, abrangendo a única espécie da seção Praeclara (Rodrigues \& Tozzi 2006). Guianodendron praeclarum (Sandwith) Sch. Rodr. \& A.M.G. Azevedo se distingue dentre as Papilionoideae pela combinação de flores radiais com cinco pétalas auriculadas, cinco estames e ovário 1(2)-ovulado (Rodrigues \& Tozzi 2006).

\footnotetext{
1 Universidade Federal de Roraima, Centro de Estudos da Biodiversidade, Boa Vista, RR, Brasil

2 Universidade Estadual de Campinas, Instituto de Biologia, Departamento de Biologia Vegetal, Campinas, SP, Brasil

3 Autor para correspondência: rodschutz@gmail.com
} 
Leptolobium pode ser distinto de Acosmium principalmente pela posição das inflorescências, arquitetura dos botões florais, forma do cálice e morfologia da semente e da plântula (Rodrigues \& Tozzi 2007a; 2008a; 2009). Em Leptolobium, as inflorescências são terminais, ocasionalmente com racemos axilares, sendo exclusivamente axilares em Acosmium. Os botões florais de Leptolobium são turbinados ou globosos, com as pétalas cobrindo os demais órgãos, os filetes fortemente inflexos e o estilete curvo enquanto que, em Acosmium, os botões florais são elipsoides, com as pétalas não cobrindo os demais órgãos, os filetes ligeiramente inflexos e o estilete reto. Em Leptolobium, os lacínios são maiores que o tubo e os dois lacínios superiores são fusionados acima dos demais e geralmente maiores. Em Acosmium, os lacínios são menores que o tubo, raramente do mesmo tamanho, e são semelhantes entre si. As sementes em Leptolobium são compressas, com funículo caduco, arilo marginal e embrião com eixo hipocótilo-radícula bulboso, paralelo ao comprimento da semente, raramente oblíquo ou transverso. Em Acosmium, as sementes são achatadas, com funículo persistente, sem arilo e embrião com eixo hipocótilo-radícula linear, transverso, raro oblíquo. Por fim, as plântulas em Leptolobium diferem das de Acosmium principalmente pelo hipocótilo quadrangular (cilíndrico em Acosmium), presença de glândulas intercotiledonares (ausentes em Acosmium) e ausência de nictinastia dos cotilédones (presente em Acosmium). Por outro lado, análises morfológicas têm evidenciado a proximidade de Leptolobium com Bowdichia Kunth, que fazem parte do clado genistoide (Pennington et al. 2001; Wojciechowski et al. 2004), compartilhando similaridades na composição de alcaloides, e na morfologia de sementes e plântulas (Rodrigues \& Tozzi 2007a; 2007b; 2008a).

A revisão de Yakovlev (1969) contemplou poucas coleções depositadas nos herbários do Brasil, onde ocorre a grande maioria das espécies de Leptolobium. Desde então, três espécies do gênero foram descritas para a América do Sul (Aymard \& González 2003; Rodrigues \& Tozzi 2010), todas ocorrentes no Brasil. Considerando ainda mudanças nomenclaturais e algumas sinonimizações em Leptolobium (Rodrigues \& Tozzi 2008b), o objetivo deste trabalho é realizar uma revisão taxonômica de Leptolobium, apresentando chave de identificação, nomenclatura, descrições, ilustrações e mapas de distribuição das espécies, bem como observações sobre similaridade fenotípica, usos, nomes populares e habitats de cada espécie.

\section{Material e métodos}

Foi realizada uma análise morfológica de exsicatas, complementada com os dados de suas etiquetas e de observações de campo, cujos exemplares coletados foram incorporados ao Herbário UEC. Foram examinadas exsicatas dos herbários $\mathrm{BHCB}, \mathrm{C}, \mathrm{CEN}$, CGMS, COL, CPAP, CVRD, ESA, F, FI, FUEL, HBG, HEPH, HRCB, HUCS, HUEFS, IAC, IAN,
IBGE, INPA, L, MG, MICH, MIRR, NY, R, RB, SP, SPF, TEPB, U, UB, UC, UEC, VEN e VIC (siglas de acordo com Thiers 2011). Em adição, foram analisadas cópias xerográficas ou imagens digitais de exsicatas dos herbários B, BR, HUH, K, MICH, MO e US. A terminologia foi baseada em Radford et al. (1974), Font Quer (1979) e Stearn (1992). As medidas do comprimento da flor incluem o pedicelo e se estendem até $\mathrm{o}$ ápice das pétalas, o comprimento das pétalas inclui as unhas, o comprimento do tubo do cálice é tomado junto aos lacínios inferiores; o comprimento do pedicelo foi considerado a distância entre a sua base e a inserção das bractéolas; e a declinação do eixo hipocótilo-radícula (paralela, oblíqua ou transversa) é considerada em relação ao comprimento da semente. Para L. araguaiense e L. multijugum, foram citados todos os materiais examinados; para as demais espécies, foi geralmente indicada apenas uma coleção por estado ou província de cada país no item material selecionado. No entanto, uma lista de exsicatas de todo material examinado é apresentada ao final do trabalho. Por fim, somente foram mapeados os indivíduos examinados, onde cada ponto pode representar uma ou mais coleções para cada localidade.

\section{Tratamento taxonômico}

Leptolobium Vogel, Linnaea 11:388. 1837 (non Leptolobium Benth., Comm. Legum. Gen.: 60. 1837). Sweetia sect. Leptolobium (Vogel) Benth., J. Linn. Soc., Bot. 8: 261. 1865. Acosmium sect. Leptolobium (Vogel) Yakovlev, Notes Roy. Bot. Gard. Edinburgh 29: 350. 1969. Tipo: L. dasycarpum Vogel (designado por Mohlenbrock 1963: 233).

Leptolobium sect. Mesitis Vogel, Linnaea 11:393. 1837. Sweetia sect. Mesitis (Vogel) Benth., J. Linn. Soc., Bot. 8: 261. 1865. Acosmium sect. Mesitis (Vogel) Yakovlev, Notes Roy. Bot. Gard. Edinburgh 29: 354. 1969. Tipo: L. bijugum Vogel.

Árvores ou arbustos. Estípulas 2-6 mm compr., linear-lanceoladas a lineares, caducas. Folhas alternas, imparipinadas, raro paripinadas, (1-)3-21 folíolos; estipelas 0,5-1,5 mm compr., lineares, caducas; folíolos com base simétrica, raramente assimétrica. Inflorescências paniculadas, terminais, muitas vezes precedidas por racemos ou panículas axilares; brácteas e bractéolas florais lineares ou linear-lanceoladas, caducas; glândulas na inserção do pedicelo e bractéolas. Botões florais turbinados ou globosos. Flores pentâmeras, hipanto reto; cálice turbinado-campanulado, lacínios maiores que o tubo, os dois lacínios superiores fusionados acima dos demais e geralmente maiores; corola actinomorfa a levemente zigomorfa, pétalas brancas, não auriculadas ou esculturadas, pétala adaxial levemente diferenciada ou não em forma e/ou tamanho das demais pétalas; estames 10 , livres, uniformes, filetes glabros ou raro esparsamente pubescentes, anteras dorsifixas, largamente elípticas, glabras; ovário estipitado, glabro, glabrescente, pubescente a tomentoso; estigma punctiforme. Legume geralmente samaroide, elíptico a oblongo, raro obovado, castanho, coriáceo, reticulado, estipitado, com ou sem 
ala sutural, ou raro legume nucoide, lenhoso, fusiforme, castanho-escuro, não reticulado e curto-estipitado. Sementes dispostas paralelamente ao comprimento do fruto, compressas, unicolores, castanhas a ferrugíneas, lobo radicular pouco ou levemente desenvolvido, arilo marginal em colar, hilo visível, apical ou subapical, raro lateral, circular a oblongo, fenda hilar visível, funículo não persistente; endosperma envolvendo a totalidade do embrião, tanto ou mais espesso que os cotilédones; eixo hipocótilo-radícula bulboso, paralelo ao comprimento da semente, raro oblíquo ou transverso; plúmula rudimentar.

Leptolobium é um gênero exclusivamente neotropical, ocorrendo desde o sul do México até o norte da Argentina. Apresenta 12 espécies, das quais 11 ocorrem no Brasil, sendo sete espécies endêmicas do país (Fig.
1-7). Yakovlev (1969) distinguiu as seções Leptolobium e Mesitis com base na curvatura da radícula, ou mais apropriadamente, do eixo hipocótilo-radícula, caráter anteriormente utilizado por Vogel (1837) e Bentham (1865). Na seção Mesitis, o eixo hipocótilo-radícula é oblíquo ou transverso em L. bijugum, mas pode ser oblíquo ou paralelo em L. brachystachyum. Por outro lado, todas as espécies da seção Leptolobium têm eixo hipocótilo-radícula paralelo, com exceção de $L$. panamense, que pode também apresentar eixo oblíquo. Considerando esta sobreposição e que outros caracteres não foram encontrados para distinguir as duas seções, Rodrigues \& Tozzi (2008b) não reconheceram uma classificação infragenérica em Leptolobium, posição que também foi adotada neste trabalho.

\section{Chave de identificação para as espécies de Leptolobium}

1. Folíolos 17-21; bráctea 0,8-1,2 mm compr.; bractéola 0,5-0,7 mm compr.

7. L. multijugum

1. Folíolos (1-)3-13(-15); bráctea 1,2-5 mm compr.; bractéola 0,8-3 mm compr.

2. Folha paripinada (raramente imparipinada no mesmo indivíduo); semente 3-4 mm larg.; embrião com eixo hipocótilo-radícula transverso ou oblíquo ao comprimento da semente

2. Folha imparipinada (raro paripinada no mesmo indivíduo); semente 4-8 mm larg.; embrião com eixo hipocótilo-radícula paralelo ou oblíquo ao comprimento da semente.

3. Legume nucoide; estípite do ovário 0,8-1,5 mm compr.; semente 3,8-4,5 mm diâm.

8. L. nitens

3. Legume samaroide, estípite do ovário 1,5-2,5 mm compr.; semente 1,5-3,5 mm diâm.

4. Semente 7,2-10 mm compr.; hilo 1,4-1,5 mm compr.; Costa Atlântica do Brasil (Rio de Janeiro à Bahia)

12. L. tenuifolium

4. Semente 5,5-7 mm compr.; hilo 0,5-1,2 mm compr.; México até o Centro e Sul-Sudeste do Brasil.

5. Ovário glabro a glabrescente, às vezes ciliado nas margens.

6. Raque foliar $1-4,5 \mathrm{~cm}$ compr.

10. L. parvifolium

6. Raque foliar $5-14 \mathrm{~cm}$ compr.

7. Bráctea 1,2-1,5 mm compr.; flor 6,5-8 mm compr.; pétala adaxial com ápice emarginado, raro truncado; hilo 0,9-1,1 x 0,5-0,6 mm, elíptico.

7. Bráctea 1,5-3 mm compr.; flor 8-12 mm compr.; pétala adaxial com ápice arredondado a truncado; hilo $0,6-0,8 \times 0,6-0,8 \mathrm{~mm}$, circular.

8. Pétala adaxial com dimensões semelhantes às demais pétalas; pecíolo 3,5-7 cm compr........... 5.L. elegans

8. Pétala adaxial menor e mais larga que as demais pétalas; pecíolo 1-3,8 cm compr. 6. L. glaziovianum

5.Ovário pubescente a tomentoso.

9. Racemo 2-5 cm compr.; folíolos oblongos; legume com ala sutural 1-1,5 mm larg.; semente 2-2,8 mm diâm.

9. Racemo 5-20 cm compr.; folíolos elípticos, ovados, ou lanceolados; legume geralmente sem ala sutural, ou se presente (L. stirtonii), então 0,5-1 mm larg. e semente 3-3,5 mm diâm.

10. Pétala adaxial com dimensões semelhantes às demais pétalas; semente 1,9-2,5 mm diâm.

11. Tubo do cálice 1,5-2,3 mm compr.; pulvínulo 0,5-3 mm compr.; ovário tomentoso .. 4. L. dasycarpum

11. Tubo do cálice 0,8-1,5 mm compr.; pulvínulo 3-8 mm compr.; ovário não tomentoso (glabro, glabrescente a pubescente)

5. L. elegans

10. Pétala adaxial menor e mais larga que as demais pétalas; sementes $3-3,5 \mathrm{~mm}$ diâm.

12. Folíolos 5-7; bractéola 1,5-2,5 mm compr; legume com ala sutural 0,5-1 mm larg. e com estípite 5-9 mm compr.; semente 5-6 4 4-5 mm; hilo ca. 0,7 x 0,7 mm ...

11. L. stirtonii

12. Folíolos 9-13; bractéola 0,8-1,1 mm compr.; legume sem ala sutural e com estípite 3-5 mm compr.; semente 7-7,2 x 5,5-6 mm; hilo 1-1,2 x 0,9-1 mm

1. L. araguaiense 
1. Leptolobium araguaiense Sch. Rodr. \& A.M.G. Azevedo, Brittonia 62: 20. 2010. Tipo: Brasil. Pará: Mun. Conceição do Araguaia, Alacilândia, $42 \mathrm{~km}$ west of Conceição do Araguaia along highway PA-287 at Rio Arraias do Araguaia, ca. $8^{\circ} 13^{\prime}$ S, $49^{\circ} 36^{\prime}$ W, 300 m, 23/II/1980, fl., T.C. Plowman et al. 9034 (Holótipo MG!; Isótipos F!, IAN!, MICH!, NY!).

Fig. 7A

Árvore 5-6 $\mathrm{m}$ alt., ramos jovens pubescentes. Folha imparipinada, 9-13 folíolos; pecíolo 1,3-2 cm compr., raque foliar 4,2-8 cm compr., ambos pubescentes; pulvínulo 2,5-3,5 mm compr.; folíolo 3-5,5 x 1,5-2,5 cm, discolor, elíptico, ambas as faces glabras, base obtusa a obliquamente cuneada, ápice acuminado a agudo. Inflorescência com eixo pubescente, racemos 8-14 cm compr.; bráctea 1,6-2,1 mm compr., bractéolas $0,8-1,1 \mathrm{~mm}$ compr. Flor 9-11 mm compr.; pedicelo 1,5-2 mm compr.; hipanto 1-1,2 $\mathrm{mm}$ compr.; cálice pubescente, tubo 1-1,5 mm compr., lacínios 2-2,5 $\mathrm{mm}$ compr.; corola glabra, pétala adaxial 5,5-6,5 x 4-5 mm, oblata a largamente obovada, ápice emarginado, demais pétalas 6,5-7,5 x 3-3,5 mm, obovadas, ápice emarginado ou premorso; filetes 7,5-8,5 mm compr., anteras $0,6-0,8$ mm compr.; ovário pubescente, 3 ou 4 óvulos, estípite 1,5-2 $\mathrm{mm}$ compr. Legume samaroide $4-6$ x 1,8-2 cm, glabro, ala sutural ausente, estípite 3-5 mm compr., 1 ou 2 sementes. Semente 7-7,2 x 5,5-6 mm, oblonga, hilo 1-1,2 x 0,9-1 mm, circular; eixo hipocótilo-radícula paralelo.

Material examinado: BRASIL. Pará: Marabá, 29/ VI/1949, fr., Fróes \& Black 24759 (IAC). Tocantins: Pium, Ilha do Bananal, 27/III/1999, fl., Mendonça et al. 4069 (NY).

Ocorre somente no Brasil (Pará e Tocantins), no Bioma Cerrado, ao longo da bacia do rio Araguaia, em campos limpos de murundus ou em vegetação secundária. Coletada com flores em fevereiro e março com frutos em junho.

Leptolobium araguaiense assemelha-se a L. panamense, diferindo pelo ovário pubescente e pelas flores e brácteas maiores. Além disso, L. araguaiense, restrita ao Brasil, é uma árvore pequena (5-6 m alt.) que ocorre em vegetação de savana ou secundária, enquanto $L$. panamense é uma árvore de grande porte (até $40 \mathrm{~m}$ alt.), com distribuição em florestas tropicais úmidas do México até a Colômbia e Venezuela. Ilustração em Rodrigues \& Tozzi (2010).

2. Leptolobium bijugum (Spreng.) Vogel, Linnaea 11: 391. 1837. Cubaea bijuga Spreng., Neue Entdeck. 1: 290. 1820. Tachigali bijuga (Spreng.) DC., Prodr. 2: 487. 1825. Sweetia bijuga (Spreng.) Benth., J. Linn. Soc., Bot. 8: 261. 1865. Acosmium bijugum (Spreng.) Yakovlev, Notes Roy. Bot. Gard. Edinburgh 29: 354. 1969. Tipo: Brasil: "F. Sellow leg. inter Victoria et Bahia" (Lectótipo K [espécime superior, à esquerda na exsicata, foto K000188700!, neg. 2798 F!, NY!], designado por Rodrigues \& Tozzi 2008b; Isolectótipos BR [foto BR842321 BR!], F 1540140!, LE, P).

Fig. 1A-I, 6A
Árvore ou arbusto (0,3-)1,3-12 m alt., tronco reto ou subprostrado, ritidoma cinza, áspero, levemente estriado, ramos glabros. Folha paripinada, raramente imparipinada no mesmo indivíduo, 4-10 folíolos; pecíolo 1,7-3,6 cm compr., raque foliar 1,5-4 cm compr., ambos glabros; pulvínulo 1,5-3 mm compr.; folíolo 1,8-4,9 x 1,2-2,9 cm, discolor, elíptico a obovado, glabro em ambas as faces, base obtusa, arredondada a cuneada, ápice obtuso a emarginado. Inflorescência com eixo glabro a pubérulo, racemos $3-20 \mathrm{~cm}$ compr.; bráctea 1,2-1,5 mm compr., bractéolas $0,8-1,3 \mathrm{~mm}$ compr. Flor 8-11 mm compr.; pedicelo 2-3,5 mm compr.; hipanto 1,4-2 mm compr.; cálice pubescente, tubo 1,5-2 mm compr., lacínios 2,3-3,5 mm compr.; corola glabra, pétala adaxial 4,3-5 x 3-4 mm, oblata, ápice emarginado a truncado, demais pétalas 6-7 x 2,5-3 mm, obovadas, ápice obtuso a arredondado; filetes $6-9 \mathrm{~mm}$ compr., anteras 1 mm compr.; ovário tomentoso, 2-4 óvulos, estípite 1,7-2,3 $\mathrm{mm}$ compr. Legume samaroide 4,2-6 x 1-1,7 cm, glabro a glabrescente, ala sutural 0,8-1,5 mm larg., estípite 7-10 mm compr., 1-4 sementes. Semente 5,5-6,5 x 3,5-4 x 1,5-2 mm, oblonga, hilo $0,5-0,6 \mathrm{x}$ ca. $0,5 \mathrm{~mm}$, circular; eixo hipocótilo-radícula tranverso ou oblíquo.

Material selecionado: BRASIL. Alagoas: Maceió, 02/ II/1982, fl., Kirkbride Jr. 4624 (F, NY, UB). Bahia: Marau, 22/V/1991, fr. imat., Carvalho et al. 3267 (HUEFS, NY, R); ibid., 06/II/1979, fl. fr., Mori et al. 11419 (NY, RB); Salvador, 21.I.1987, fl., Harley \& Guedes 24108 (NY). Espírito Santo: Linhares, 25/VI/2003, fr., Rodrigues et al. 1600 (CVRD, MIRR, UEC). Sergipe: Estância, 28/XI/1993, fl., Amorim et al. 1535 (NY).

Ocorre somente no Brasil (Espírito Santo, Bahia, Sergipe e Alagoas), no Bioma Mata Atlântica, em diferentes ambientes de restinga, como dunas, campos arenosos e matas. Coletada com flores de outubro a fevereiro e em maio e com frutos em fevereiro, maio, junho, agosto e outubro. Conhecida como macanaíba-do-nativo e angico-do-litoral.

Leptolobium bijugum é a única espécie do gênero com folhas paripinadas, raramente apresentando folhas imparipinadas no mesmo indivíduo. Suas sementes são também as únicas do gênero com eixo hipocótilo-radícula transverso ao comprimento da semente, embora eixo oblíquo também seja encontrado.

3. Leptolobium brachystachyum (Benth.) Sch. Rodr. \& A.M.G. Azevedo, Taxon 57(3): 981. 2008. Sweetia brachystachya Benth., J. Linn. Soc., Bot. 8: 262. 1865. Acosmium brachystachyum (Benth.) Yakovlev, Notes Roy. Bot. Gard. Edinburgh 29: 354. 1969. Tipo: Brasil, Minas Gerais, "Hab. Serra da Lapa, Riedel” (Holótipo K, L. Riedel "191 also 56" [foto neg. 2799 F!, NY!]; Isótipos GH [foto GH 63552!], LE).

Fig. 1J-R, 6B

Árvore ou arvoreta 1-5 m alt., tronco reto, ritidoma liso, cinza, ramos glabros. Folha imparipinada, raro paripinada, 7-11 folíolos; pecíolo 1,3-3,5 cm compr., raque foliar 2-6 
cm compr., ambos glabros a esparsamente pubescentes; pulvínulo $2-5 \mathrm{~mm}$ compr., folíolo 1,3-4,5 x 0,6-2,1 cm, discolor, oblongo, glabro em ambas as faces, base obtusa, ápice emarginado ou obtuso. Inflorescência com eixo glabro a pubescente, racemos 2-5 $\mathrm{cm}$ compr.; bráctea 1,5-2,7 mm compr., bractéolas $0,8-1,6 \mathrm{~mm}$ compr. Flor 8-11 mm compr.; pedicelo 1,5-2,5 mm compr.; hipanto 1,2-2 $\mathrm{mm}$ compr.; cálice glabrescente, tubo 1,3-1,5 mm compr., lacínios 2-2,6 mm compr.; corola glabra, pétala adaxial 7-8,3 x 2,5-3,5 mm, obovada, ápice arredondado, demais pétalas 7-8 x 2,3-2,6 $\mathrm{mm}$, obovadas, ápice arredondado; filetes $6-8 \mathrm{~mm}$ compr., anteras ca. $1 \mathrm{~mm}$ compr.; ovário tomentoso, 3-5 óvulos, estípite 2-2,8 mm compr. Legume samaroide 1,8-5 x 1-1,8 $\mathrm{cm}$, glabro, ala sutural 1-1,5 mm larg., estípite 5,5-10 mm compr., 1-3 sementes. Semente 5,5-7 x 4-5 x 2-2,8 mm, oblonga, hilo ca. 0,6 x 0,6 mm, circular; eixo hipocótilo-radícula paralelo ou oblíquo.

Material selecionado: BRASIL. Minas Gerais: Diamantina: 14/IV/1973, fr., Anderson et al. 8892 (NY, UB); Itacambira, 13/XI/2001, fl. fr., Rodrigues et al. 1293 (MIRR, UEC); Joaquim Felício, 17/XI/1997, fl., Hatschbach et al. 67167 (C, ESA, HBG, HRCB, HUCS, HUEFS, NY).

Ocorre somente no Brasil (Minas Gerais), no Bioma Cerrado, na Serra do Espinhaço, preferencialmente em campos rupestres, ou em campos arenosos úmidos adjacentes. Coletada com flores em maio e de outubro a fevereiro e com frutos em novembro e de janeiro a abril.

Leptolobium brachystachyum é distinta das demais espécies do gênero pela combinação de folíolos oblongos e discolores e pelas inflorescências curtas, com racemos reduzidos (até $5 \mathrm{~cm}$ compr.).

4. Leptolobium dasycarpum Vogel, Linnaea 11: 388. 1837. Sweetia dasycarpa (Vogel) Benth., J. Linn. Soc., Bot. 8: 262. 1865. Acosmium dasycarpum (Vogel) Yakovlev, Notes Roy. Bot. Gard. Edinburgh 29: 351. 1969. Tipo: Brasil, "Sellow leg. in prov. Minas Geraes pr. Capivary, S. Antonio de Monte, Pirapitinga alliesque locis" (Lectótipo K [fotos K000500794!, foto neg. 2800 F!, NY!], designado por Mohlenbrock 1963 [primeiro passo] e por Rodrigues \& Tozzi 2008b [segundo passo, Art. 9.15]; Isolectótipo US [foto 2894 US!]).

Leptolobium lanceolatum Tul., Arch. Mus. Hist. Nat. 4: 118. 1844. Tipo: Brasil, Pará, "herb Mus. Par. ex herb. Ulysippon” [sic], s.col. (P [foto P 00312232!]).

Leptolobium glabrifolium Tul., Arch. Mus. Hist. Nat. 4: 119. 1844. Sweetia glabrifolia (Tul.) Benth., J. Linn. Soc., Bot. 8: 262. 1865. Tipo: Brazil, Ceará, G. Gardner 1570 (Lectótipo P, designado por Bridgewater \& Stirton 1997; Isolectótipos K! [foto F!, NY!]).

Sweetia dasycarpa var. glabrata Benth. in Mart., Fl. Bras. 15(2): 6. 1870. Acosmium dasycarpum subsp. glabratum (Benth.) Yakovlev, Notes Roy. Bot. Gard. Edinburgh 29: 351. 1969. Tipo: Brasil, Minas Gerais, s.loc., A.F.M. Glaziou 12603 (Lectótipo GH [foto $63553 \mathrm{GH}$ !], designado por Mohlenbrock 1963 [primeiro passo] e por Yakovlev 1969: 352 [segundo passo, Art. 9.15]; Isolectótipos K [foto!], LE, NY!, P, R!).

Sweetia handroi Mohlenbr., Webbia 17: 246. 1963. Tipo: Brasil, São Paulo, Mogi-Guaçu, Reserva Florestal, $O$. Handro 445 (Holótipo MO [foto MO!]; Isótipo SP!). Leptolobium tortum Mart., Herb. Fl. Bras. n. 1151. cat. aut. Leptolobium tortuosum Mart. ex Benth., J. Linn. Soc., Bot. 8: 262. 1865, pro syn., nom. inval.

Fig. 2A-I, 7B

Árvore ou arvoreta 1-10 m alt., tronco geralmente tortuoso, ritidoma castanho ou cinza, suberoso, com profundas fissuras longitudinais, ramos pubescentes a glabros. Folha imparipinada, (1-)3-9 folíolos; pecíolo 1,5-6 cm compr., raque foliar 3,2-10 cm compr., ambos pubescentes a glabros; pulvínulo 0,5-3 mm compr.; folíolo 4-15 x 2-9 cm, concolor, ovado a elíptico, face adaxial glabra, abaxial glabra a densamente pubescente, base obtusa a cordada, ápice obtuso a emarginado. Inflorescência com eixo densamente pubescente a glabrescente, racemos 5-20 cm compr.; bráctea 2,5-5 mm compr., bractéolas 1,5-3 mm compr.. Flor 7-13 mm compr.; pedicelo 0,7-2(-3) mm compr.; hipanto 1,3-2 $\mathrm{mm}$ compr.; cálice pubérulo a densamente pubescente, tubo 1,5-2,3 mm compr., lacínios 2-3,1 mm compr., corola glabra ou raro com longos tricomas alvos, pétala adaxial 4,5-8 $\mathrm{x}$ 1,8-4 mm, obovada, ápice arredondado ou truncado, demais pétalas 4,5-8,2 x 1,7-3,8 mm, obovadas, ápice arredondado ou truncado; filete 7-11 mm compr., antera 0,9-1,2 mm compr.; ovário tomentoso, 4 ou 5 óvulos, estípite 1,8-3,5 $\mathrm{mm}$ compr. Legume samaroide $4-7 \times 1,3-2,5 \mathrm{~cm}$, glabro ou esparsamente pubescente, ala sutural ausente, estípite 3,5-12 mm compr., 1-3 sementes. Semente 4,5-7 x 4-6 x $1,9-2,5 \mathrm{~mm}$, ovada a suborbicular, hilo $0,5-0,7 \times 0,5-0,7 \mathrm{~mm}$, circular; eixo hipocótilo-radícula paralelo.

Material selecionado: BOLÍVIA. Sandoval: Santa Cruz, San Matias, IV/1980, fr., Krapovickas \& Schinini 36287 (NY). BRASIL. Bahia: Barra da Estiva, 17/I/2002, fl., Rodrigues et al. 1315 (MIRR, UEC). Ceará: Araripe, s.d., est., Allemão \& Cyneiros 442 (R). Distrito Federal: Brasília, 04/X/1965, fl. fr. imat., Irwin et al. 8939 (C, F, NY). Id., 24/X/1981, Pereira 118 (IBGE). Goiás: Itumbiara, 17/XI/1973, fl., Hatschbach 33365 (C, NY, MICH, UEC). Maranhão: Santa Quitéria, 24/IV/1999, fl., Líbano 11 (MG). Mato Grosso: Cáceres, 30/X/1985, fl., Ferreira et al. 6561 (F, MICH, NY). Cuiabá: 07/III/1983, fr., Macedo \& Assumpção 1748 (UEC). Mato Grosso do Sul: Selviria, 06/XI/1985, Martins et al. 68 (SP, UEC). Minas Gerais: Itutinga, 12/X/2001, fr., Rodrigues et al. 1207 (UEC). Jaboticatubas, 21/XI/2000, fl., Rodrigues \& Tozzi 1001 (UEC). Piauí: Piracuruca, 04/IV/2002, fr. imat., Rodrigues et al. 1476 (UEC). Rondônia: Vilhena, 31/X/1979, fl., Nelson et al. 341 (NY). São Paulo: Mogi-Guaçu, 19/ XI/1980, fl., Mantovani 1365 (NY, SP, UEC). Tocantins: Ilha do Bananal, 22/V/1979, Pires \& Santos 16968 (MG).

Ocorre na Bolívia e no Brasil, no Bioma Cerrado, em diferentes fitofisionomias de savana, como cerrado s. str., 


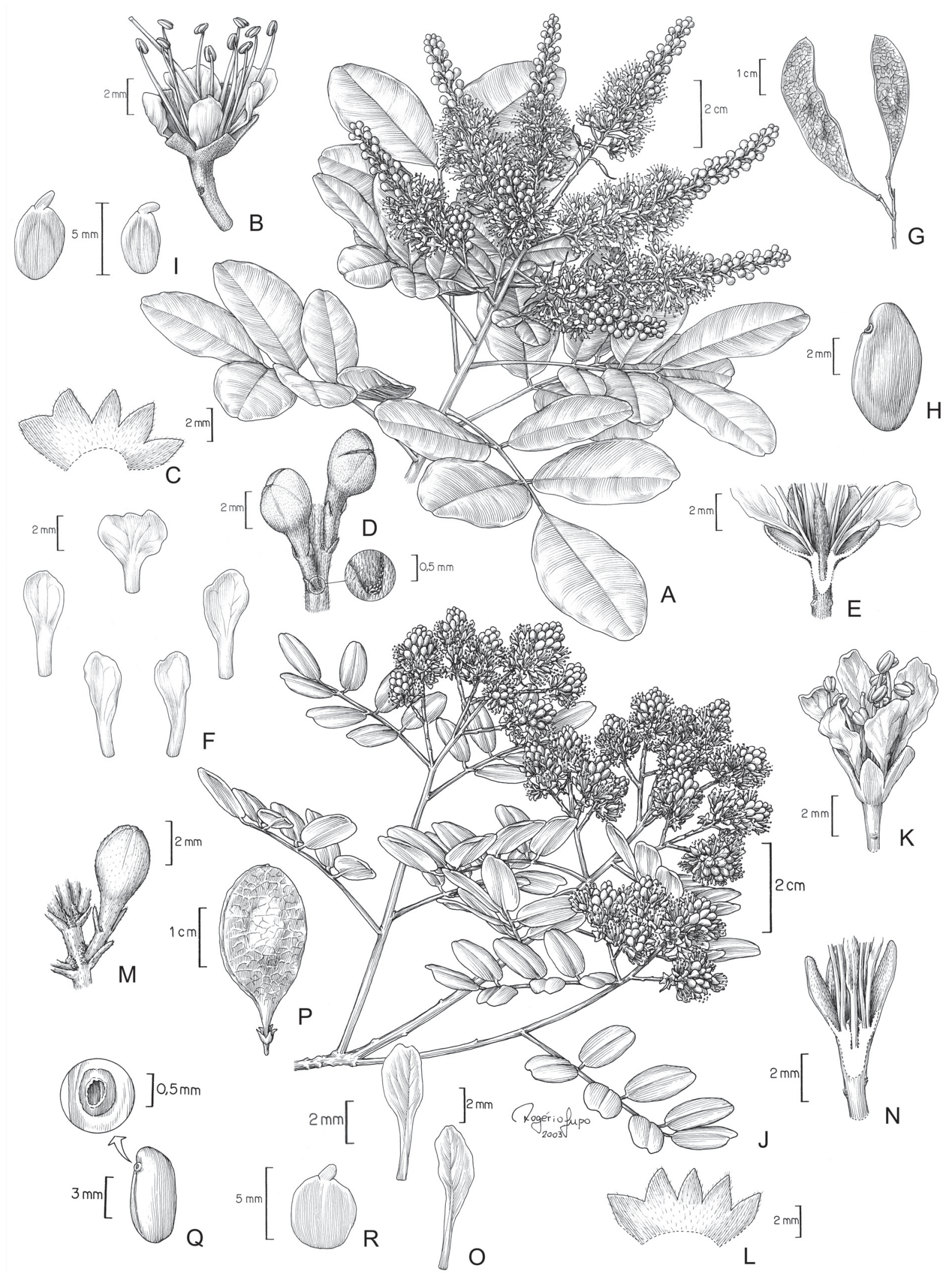

Figura 1. A-I. Leptolobium bijugum (Spreng.) Vogel. A. Ramo com flores. B. Flor. C. Cálice. D. Botões florais, com glândulas na inserção do pedicelo. E. Corte longitudinal da flor. F. Pétalas adaxial (acima) e laterais e abaxiais (abaixo). G. Frutos. H. Semente. I. Embriões. J-R. Leptolobium brachystachyum (Benth.) Sch. Rodr. \& A.M.G. Azevedo. J. Ramo com flores. K. Flor. L. Cálice. M. Botão floral. N. Corte longitudinal da flor. O. Pétalas adaxial (acima) e lateral. P. Fruto. Q. Semente, destacando o hilo com arilo marginal. R. Embrião (A: Viana 4; B, D-F: Harley \& Guedes 24108; C: Mori et al. 11419; G-I: Rodrigues et al. 1600; J-O: Rodrigues et al. 1293; P-R Anderson et al. 8892). 
campos rupestres, cerradão e borda de mata ciliar e também em áreas de transição com o Bioma Caatinga. Coletada com flores em julho e de outubro a abril e com frutos de setembro a junho. Conhecida como romã-brava, pau-pratudo, perobinha, perobinha-de-chapada, unha-de-anta, amargozinho, amargosa e cascudinho (Brasil).

Leptolobium dasycarpum apresenta a distribuição mais ampla no Brasil, somente não ocorrendo na região sul do país. Esta espécie, juntamente com L. nitens, apresenta a maior variação com relação à pubescência das partes vegetativas. Devido à presença de indivíduos com folíolos densamente pubescentes e outros com folíolos glabros na face abaxial, duas variedades já foram reconhecidas para esta espécie (Bentham 1870; Mohlenbrock 1963; Yakovlev 1969). Entretanto, Bridgewater \& Stirton (1997) verificaram a ocorrência de espécimes intermediários, sendo que as formas glabras e pubescentes não apresentaram separação geográfica, não justificando a manutenção de variedades em L. dasycarpum, o que foi seguido neste trabalho.

Para L. dasycarpum, caracteres constantes ao longo de sua distribuição são o ovário tomentoso, as brácteas e bractéolas relativamente grandes, a pétala adaxial não diferenciada e os pulvínulos curtos. Comumente $L$. dasycarpum é curto-pedicelada (0,7-1,5 mm compr.), mas uma coleção de Rondônia (Nelson et al. 341) apresentou pedicelo até $3 \mathrm{~mm}$ compr. Em geral, as pétalas são glabras, mas um indivíduo do Distrito Federal foi observado com todas as pétalas esparsamente pubescentes na unha e base da lâmina (Azevedo 334).

Leptolobium dasycarpum é próxima de L. parvifolium (ver discussão nesta espécie) e também semelhante a $L$. elegans, da qual difere principalmente pelos pulvínulos menores, tubo do cálice maior, ovário tomentoso e por apresentar brácteas e bractéolas geralmente maiores.

5. Leptolobium elegans Vogel, Linnaea 11:390. 1837. Sweetia elegans (Vogel) Benth., J. Linn. Soc., Bot. 8: 262. 1865. Tipo: Brasil, "Sellow leg. in San Paulo pr. Ypanéma, in Minas Geraes Capibury alliesque locis" (Lectótipo F 1540595!, designado por Rodrigues \& Tozzi 2008b; Isolectótipos K [foto neg. $2801 \mathrm{~F}$ !, NY!], LE, US).

Sweetia subelegans Mohlenbr., Webbia 17: 251. 1963. Acosmium subelegans (Mohlenbr.) Yakovlev, Notes Roy. Bot. Gard. Edinburgh 29: 353. 1969. Tipo: Brasil, s.loc., F. Sellow s.n. (Lectótipo US 2253985 [foto US 2893!], designado por Rodrigues \& Tozzi 2008b; Isolectótipos F 1540139!, GH [foto GH], US [63555!], LE, K [foto neg. $2801 \mathrm{NY}$ !]).

Sweetia elegans f. oblongifolia Chodat \& Hassl., Bull. Herb. Boiss., ser. 2, 4: 834. 1904. Síntipo: Paraguai, Atirá, E. Hassler 3546 (G); Paraguay, Cordillera de Altos, E. Hassler 2982 (G, F!, UC!).

Sweetia elegans f. ovalifolia Chodat \& Hassl., Bull. Herb. Boiss., ser. 2, 4: 834. 1904. Tipo: Paraguai, Nandurucay Sierra de Maracayu, E. Hassler 4919 (Holótipo G; Isótipos F!, NY!, P! [foto P00634413!], UC!).
Leptolobium elegans var. grandiflora Vogel ex Mohlenbr., Webbia 17: 250. 1963, nom. nud.

Leptolobium elegans var. parviflora Vogel ex Mohlenbr., Webbia 17: 250. 1963, nom. nud.

Fig. 2J-R, 6A

Árvore ou arvoreta 1,5-18 m alt., tronco geralmente tortuoso, ritidoma castanho ou cinza, suberoso, com profundas fissuras longitudinais, ramos glabros a pubescentes. Folha imparipinada, 5-11 folíolos; pecíolo 3,5-7 cm compr., raque foliar 6-11 cm compr., ambos glabros a pubescentes; pulvínulo 3-8 mm compr.; folíolo 2-8,5 x 0,8-4 cm, concolor, elíptico, ovado a lanceolado, glabro em ambas as faces, base cuneada, ápice emarginado. Inflorescência com eixo glabro a pubescente, racemos 5-12 cm compr.; bráctea 2-3 $\mathrm{mm}$ compr., bractéolas $0,8-2,2 \mathrm{~mm}$ compr. Flor 8-12 mm compr.; pedicelo 1,5-2,5 mm compr.; hipanto 1,2-1,8 mm compr.; cálice glabro a pubescente, tubo $0,8-1,5 \mathrm{~mm}$ compr., lacínios 1,7-2,5 mm compr.; corola glabra, pétala adaxial 5-6,8 x 2,5-3,4 mm, obovada, ápice arredondado, demais pétalas 5-7 x 2,5-3,2 mm, obovadas, ápice arredondado; filetes 7,5-9,5 mm compr., anteras $1 \mathrm{~mm}$ compr.; ovário glabro, glabrescente a pubescente, 3 ou 4 óvulos, estípite 1,5-2,5 mm compr. Legume samaroide 2-6 x 1-1,8 cm, glabro, ala sutural ausente, estípite 4-7 mm compr., 1-3 sementes. Semente 5,5$6,5 \times 4,5-5,5 \times 2-2,5 \mathrm{~mm}$, suborbicular a ovada, hilo 0,6-0,7 x 0,6-0,7 mm, circular; eixo hipocótilo-radícula paralelo.

Material selecionado: ARGENTINA. Misiones: San Ignacio, 16/XII/1983, fl., Cabral et al. 349 (F, MICH, UC). BRASIL. Goiás: Cachoeira Alta, 14/IV/2001, fr., Rodrigues \& Flores 1169 (MIRR, UEC). Mato Grosso: Miranda, 12/X/1972, fl., Hatschbach \& Scherer 30396 (C, NY, MICH, UC, UEC). Mato Grosso do Sul: Bela Vista, 10/II/1993, fr., Hatschbach et al. 58810 (C, HBG, HUCS, HUEFS, UEC). Minas Gerais: Carrancas, 14/X/2001, fl. fr., Rodrigues et al. 1243 (UEC). Paraná: Sengés, 19/I/1965, fr. Smith et al. 14847 (B, F, NY, R). São Paulo: Campinas, 08/X/2000, fr., Rodrigues \& Flores 993 (UEC). PARAGUAI. Alto Paraná: Itaquyry, 09/X/1995, fl., Schinini \& Marmori 29963 (NY). Caaguazú: in regione fluminis Yhú, XI/1905, fl., Hassler 9624 (NY). Caazapá: Colônia 3 de Mayo, 23/III/1993, fr., Schinini et al. 27846 (C, F, MICH, NY, U). Central: Assunción, 02/XI/1995, Landrum et al. 8729 (NY, UB). Chaco: ad ripam occidentalem flum. Paraguay, X/1903, fl., Hassler 2412 (MICH, NY, UC). San Pedro: Alto Paraguay, Primavera, 17/ XI/1957, fl., Woolston 908 (UC).

Ocorre na Argentina, Paraguai e Brasil, no Bioma Cerrado, em diferentes fitofisionomias de savana e em florestas baixas semideciduais. Coletada com flores de setembro a fevereiro, em abril, junho e julho e com frutos de outubro a maio e em julho. Conhecida como amendoim-falso, chapadinha, sucupira-branca, genciana, cascudinho, perobinha-do-campo, leptolóbio, óleo-bálsamo-do-campo (Brasil) e incienso-del-campo (Paraguai). Leptolobium elegans tem propriedades medicinais e é utilizada pela madeira, como forrageira e apícola (Lorenzi 1992; Pott \& Pott 1994). 


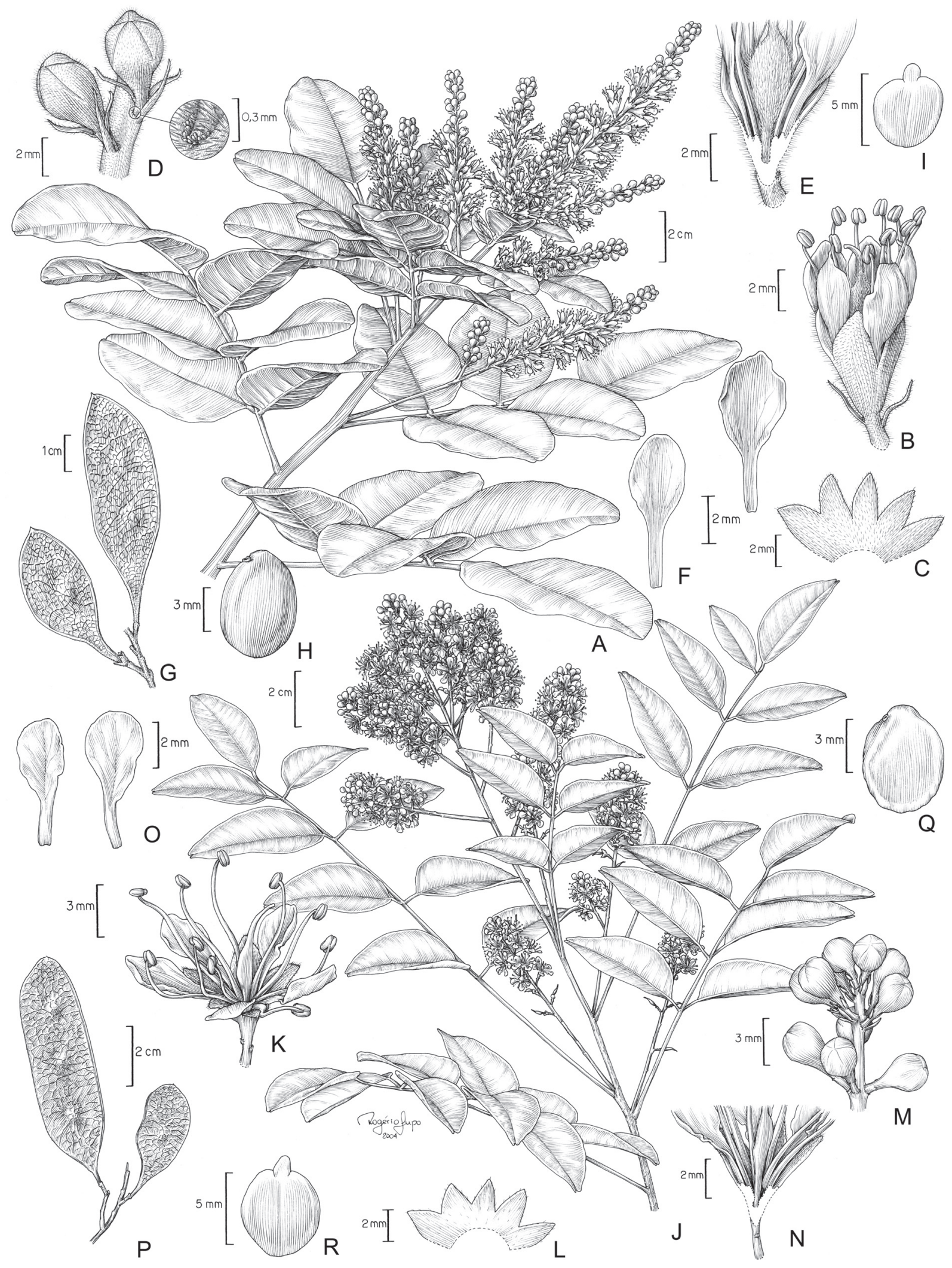

Figura 2. A-I. Leptolobium dasycarpum Vogel. A. Ramo com flores. B. Flor. C. Cálice. D. Botões florais, com glândulas na inserção do pedicelo. E. Corte longitudinal da flor. F. Pétalas adaxial (acima) e lateral. G. Frutos. H. Semente. I. Embrião. J-R. Leptolobium elegans Vogel. J. Ramo com flores. K. Flor. L. Cálice. M. Botões florais. N. Corte longitudinal da flor. O. Pétalas adaxial (à esquerda) e lateral. P. Frutos. Q. Semente. R. Embrião (A-B, D-F: Rodrigues e Tozzi 1001; C: Pereira 118; G: Macedo \& Assunção 1748; H: Rodrigues et al. 1207; I: Heringer 3254; K-Q: Rodrigues \& Flores 993; R: Rodrigues \& Flores 1169). 
Esta espécie apresenta uma história taxonômica complexa, discutida detalhadamente por Rodrigues \& Tozzi (2008b). A análise morfológica de várias coleções mostrou que a pubescência, especialmente a do ovário, pode variar em indivíduos localizados na mesma localidade. Deste modo, a delimitação de L. elegans adotada neste trabalho inclui tanto espécimes glabros, que correspondem a Sweetia subelegans Mohlenbr., quanto esparsamente pubescentes, que estão de acordo com o tipo de L. elegans. Assim, concordando com Bentham (1870), que também mencionou a variação na pubescência do ovário nesta espécie (como Sweetia elegans), Rodrigues \& Tozzi (2008b) propuseram a sinonimização de S. subelegans em L. elegans, aceita aqui, e a lectotipificação para ambos os nomes.

Leptolobium elegans pode ser confundida com $L$. dasycarpum, da qual se separa pelos caracteres enunciados na chave, e com L. tenuifolium e L. stirtonii (ver discussão nestas espécies).

6. Leptolobium glaziovianum (Harms) Sch. Rodr. \& A.M.G. Azevedo, Taxon 57 (3): 983. 2008. Sweetia glazioviana Harms, Bot. Jahrb. Syst. 33 Beibl. 72:26. 1903. Acosmium glaziovianum (Harms) Yakovlev, Notes Roy. Bot. Gard. Edinburgh 29: 352. 1969. Tipo: Brasil, Minas Gerais, "Faria, bei Sabara", A.F.M. Glaziou 18207 (Holótipo B, destruído [foto neg. 1874 F!, NY! GH!]; Lectótipo K [foto K000500791 K!], aqui designado; Isolectótipos F! [fragmento], GH, LE, P, RB! [fragmento]).

Fig. 3A-H, 6B

Árvore 4-14 m alt., ramos jovens pubescentes. Folha imparipinada, 7-13 folíolos; pecíolo 1-3,8 cm compr., raque foliar 5-12 cm compr., ambos pubescentes; pulvínulo 3-5 mm compr., pubescente; folíolo 3,3-8 x 1,3-4 cm, discolor, elíptico a oblongo, face adaxial glabra, abaxial pubescente a glabrescente, base obtusa a cuneada, ápice obtuso a truncado. Inflorescência com eixo pubescente, racemos $5-11 \mathrm{~cm}$ compr.; bráctea 1,5-2,5 mm compr., bractéolas 1-1,5 mm compr. Flor 8-11 mm compr.; pedicelo 2-3 mm compr.; hipanto 1-1,5 mm compr.; cálice pubescente, tubo 0,9-1,1 mm compr., lacínios 2-3 mm compr.; corola glabra, pétala adaxial 4,5-6 x 3-3,5 mm, oblata a obovada, ápice arredondado a truncado, demais pétalas 5,5-8 × 2,2-2,7 $\mathrm{mm}$, obovadas, ápice arredondado a truncado; filetes $7-9 \mathrm{~mm}$ compr., anteras $0,5-0,8 \mathrm{~mm}$ compr.; ovário glabro a glabrescente, $4 \mathrm{ou}$ 5 óvulos, estípite 2-2,5 mm compr. Legume samaroide, 7-9 $\mathrm{x} 1,5-1,7 \mathrm{~cm}$, glabro, glabrescente a pubescente, ala sutural ausente, estípite 6-9 mm compr., 3 ou 4 sementes. Semente 6,5-7 x 4-4,8 x 2,1-2,5 mm, oblonga, hilo 0,7-0,8 x 0,7-0,8 $\mathrm{mm}$, circular; eixo hipocótilo-radícula paralelo.

Material selecionado: BRASIL. Distrito Federal: Brasília, 15/X/1993, fr., Caetano 25 (HEPH). Minas Gerais: Belo Horizonte, Serra do Curral, XI.1956, fl., Roth 1856 (RB); Ouro Preto, 27/III/1977, fl., Badini s.n. (RB 202692). S.loc.: s.d., s.col. (RB 38476).

Ocorre somente no Brasil (Minas Gerais e Distrito
Federal), no Bioma Cerrado, em borda de mata ciliar e no cerrado s. str. Coletada com flores em janeiro, março e novembro e com frutos em abril, maio e outubro. Conhecida como sobral.

Esta espécie é similar vegetativamente a $L$. dasycarpum, da qual pode ser distinta pelas brácteas e bractéolas menores, pela pétala adaxial diferenciada e ovário glabro a esparsamente pubescente. Rodrigues \& Tozzi (2008b) se abstiveram de designar um lectótipo para Sweetia glazioviana Harms, pois até aquele momento haviam examinado somente dois isótipos fragmentados, nos herbários F e RB. Posteriormente, no entanto, foi encontrado um isótipo em K, que é aqui designado como lectótipo de S. glazioviana Harms.

7. Leptolobium multijugum Sch. Rodr. \& A.M.G. Azevedo, Brittonia 62: 24. 2010. Tipo: Brasil. Mato Grosso: Ponte Branca, 20/I/1988, A.E. Ramos 397 (Holótipo UB!; Isótipos INPA!, RB!).

Fig. 6B

Árvore $18 \mathrm{~m}$ alt., ramos jovens pubescentes. Folha imparipinada ou paripinada, 17-21 folíolos, pecíolo 1,7-2,2 cm compr., raque foliar $15,5-19 \mathrm{~cm}$ compr., ambos pubescentes; pulvínulo 2,5-3,5 mm compr.; folíolo 4,5-7 x 2,5-3,5 cm, ligeiramente discolor, oblongo a oblongo-elíptico, face adaxial glabra, abaxial pubescente, base obtusa a obliquamente cuneada, ápice retuso ou emarginado. Inflorescência com eixo pubescente, racemos 10-20 cm compr.; bráctea 0,8-1,2 $\mathrm{mm}$ compr., bractéolas 0,5-0,7 mm compr. Flor 6-8 mm compr.; pedicelo 1,2-2,1 mm compr.; hipanto 0,7-1 mm compr. Cálice pubescente, tubo 1-1,2 mm compr., lacínios 1,5-1,8 mm compr.; corola glabra, pétala adaxial 3,7-5 x 2,5-3 mm, largamente obovada a oblata, ápice emarginado, demais pétalas 4,5-5,2 x 2-2,2 mm, obovadas, ápice obtuso ou premorso; filetes 4-6 mm compr., anteras 0,5-0,6 mm compr.; ovário pubescente, 3 óvulos, estípite 1,5 mm compr. Frutos e sementes não vistos.

Material examinado: BRASIL. Goiás: s.loc., ad Serra d'Estrella, fl., s.d., Pohl 248b (NY).

Ocorre somente no Brasil (Goiás e Mato Grosso), no Bioma Cerrado, em borda de matas ripárias. Espécie pouco conhecida, cujo tipo foi coletado com flores em janeiro.

Esta espécie se distingue em Leptolobium pela associação do maior número de folíolos e pelas brácteas, bractéolas e flores relativamente pequenas. Ilustração em Rodrigues \& Tozzi (2010).

8. Leptolobium nitens Vogel, Linnaea 11:394. 1837. Sweetia nitens (Vogel) Benth., J. Linn. Soc., Bot. 8: 262. 1865. Acosmium nitens (Vogel) Yakovlev, Notes Roy. Bot. Gard. Edinburgh 29: 353. 1969. Tipo: Guiana Francesa: Cayenne, Martin s.n. (Holótipo B destruído [foto neg. 1875 F!, NY!]; Isótipo P).

Leptolobium nitidulum Miq., Stirp. Surinam. Select.: 18. 1851. Tipo: Suriname, F.W. Hostmann 1164 (Holótipo provavalmente em U; Isótipos $\mathrm{K}$ [foto $\mathrm{K} 000500788$ !, foto neg. $2803 \mathrm{NY}$ !], NY!). 
Sweetia tomentella Mohlenbr., Webbia 17: 242. 1963. Acosmium tomentellum (Mohlenbr.) Yakovlev, Notes Roy. Bot. Gard. Edinburgh 29: 352. 1969. Tipo: Brasil, Roraima, "Boa Vista, Rio Branco", J.G. Kuhlmann 746 (Holótipo SP; Isótipos RB 3239!, U!, US [foto 2890 US!]).

Fig. 3I-Q, 6B

Árvore 3-30 m alt., ramos glabros. Folha imparipinada, 3-9 folíolos; pecíolo 3,2-6 cm compr., raque foliar 3,2-9 cm compr., ambos pubérulos a glabros; pulvínulo $3,5-10 \mathrm{~mm}$ compr.; folíolo 3,9-11 x 2,1-6 cm, concolor ou levemente discolor, ovado, lanceolado a elíptico, face adaxial glabra, abaxial glabra ou pubescente, base obtusa, ápice obtuso ou emarginado. Inflorescência com eixo pubescente a glabrescente, racemos 5-20 cm compr.; bráctea 1,7-3,5 mm compr., bractéolas 1,2-2,6 mm compr. Flor 6-9 mm compr.; pedicelo 0,5-1,5 mm compr.; hipanto 0,9-1,2 $\mathrm{mm}$ compr.; cálice pubérulo a densamente pubescente, tubo $0,8-1,1 \mathrm{~mm}$ compr., lacínios 2-2,5 $\mathrm{mm}$ compr., corola glabra, pétala adaxial 4,6-5,2 x 2,5-3 mm, oblata a largamente obovada, ápice emarginado, demais pétalas 5,5-6,5 x 2,1-2,5 mm, obovadas, ápice levemente emarginado a arredondado, filetes 7,2-8 mm compr., anteras 0,5-0,7 mm compr.; ovário glabro, glabrescente, às vezes ciliado nas margens, a tomentoso, 3 óvulos, estípite 0,8-1,5 mm compr. Legume nucoide 2,2-3,3 x 1,2-2 cm, glabro, ala sutural ausente, subséssil, estípite 0,8-1,5 mm compr., 1-3 sementes. Semente 9-12 x 5,5-8 x 3,8-4,5 mm, oblongo-elíptica, hilo 1,1-1,5 x 0,9-1,1, elíptico; eixo hipocótilo-radícula paralelo.

Material selecionado: BOLÍVIA. Velasco: Santa Cruz, 28/VI/1991, fr., Nee 41519 (NY). BRASIL. Amapá: Porto Platon, rio Araguari, 16/VIII/1961, fr., Pires et al. 50355 (NY). Amazonas: Manaus, 22/III/1971, fl., Prance et al. 11505 (COL, F, INPA, MICH, NY); ibid., 18/04/1937, fl., Ducke 458 (NY). Mato Grosso: Xavantina, 12/V/1968, fr., Ratter et al. 1397 (IAN, NY, U). Pará: Oriximiná, 09/ VIII/1986, fl., Ferreira et al. 7646 (F, INPA, MG, MICH, NY); Jacundazinho, 05/07/1949, fr., Black 49-07993 (NY); Porto Trombetas, 08/12/1993, fr., Faria \& Silva 621 (RB). Rondônia: Porto Velho, 19/VI/1986, fr., Ferreira et al. 7517 (F, INPA, MG, NY). Roraima: Boa Vista, 11/II/1977, fr., Rosa \& Cordeiro 1430 (MG, NY). Tocantins: Pium, 28/ III/1999, fr., Silva et al. 4203 (IBGE, NY). COLÔMBIA. Amazonas: Araracuara, 10-22/XI/1982, fr., Idrobo et al. 11365 (COL). Meta: Coitara, 28/IV/1979, Davidse 16840 (COL, NY). Vaupés: Mitu, 03/VII/1975, fl., Zarucchi 1382 (COL). Vichada: Las Palmas, 6-19/VII/1969, fl., Bunting et al. 3605 (U). GUIANA. Kusiki Falls, 15/VIII/1952, fl., Forest Dept. 7052 (MICH). Berbice-Coryntine: along Canje River, 11/IV/1987, Pipoly et al. 11419 (COL, F, NY, U). Cuyuni-Mazaruni: near Kumaka Falls, 28/V/1989, fr., Gillespie \& Persaud 1450 (U). Siparuni Potaro: Iwokrama Rainforest Reserve, 20/III/1996, fl., Clarke 1379 (NY). Upper Takutu Upper Essequibo: Lethem, 27/IX/1990, fr., McDowell 3400 (COL, U). West Demerara: Mabura Hill, 06/IV/1988, fr., ter Steege \& de Jager 318 (NY, U). GUIANA FRANCESA.
Sinnamary river, 06/IX/1993, est., Mori et al. 23644 (NY). SURINAME. Hannover, 10/IV/1975, fr., Teunissen 15444 (U). Nickerie, 06/IX/1980, fr., Lindeman et al. 178 (COL, U). VENEZUELA. Amazonas: Rio Negro, 25/07/1984, fl., Davidse et al. 27897 (NY). Anzoategui: rio Mapire, 10/VIII/1986, fl., Rosales \& Valles 8 (NY). Apure: Pedro Camejo, 06-07/V/1977, fr., Davidse \& González 12736 (U). Anzoátegui: Rio Mapire, 10/VIII/1986, fl., Rosales \& Valles 8 (NY). Bolívar: Reserva Florestal “La Paragua”, II/1970, fr., Blanco 700 (U). Guárico: Infante, XII/1981, fr., Delascio et al. 11223 (VEN).

Ocorre na Bolívia, Colômbia, Guiana, Guiana Francesa, Suriname, Venezuela e Brasil, no Bioma Amazônia. Citações desta espécie para o Rio de Janeiro, Paraná e Bahia (Mohlenbrock 1963) não são confirmadas neste trabalho. Habita matas de igapó, bordas de mata de galeria e em matas de terra firme. Coletada com flores de fevereiro a novembro e com frutos de junho a dezembro e em fevereiro. Conhecida como itauba-rana, darura, tentinho (Brasil), kamarakata (Guiana), Watergroenhart, Watragrien, Siritjo, Hoerowassa (Suriname) e congrio (Venezuela).

É a única espécie de Leptolobium a apresentar legume nucoide, tipo de fruto muitas vezes associado à dispersão hidrocórica (Barroso et al. 1999). Além disso, os legumes desta espécie são subsésseis, apresentando o menor comprimento de estípite dentre as espécies de Leptolobium. Materiais floríferos de L. nitens são às vezes confundidos com os de L. stirtonii, mas podem ser distintos por apresentarem pedicelo e estípite do ovário menores.

9. Leptolobium panamense (Benth.) Sch. Rodr. \& A.M.G. Azevedo, Taxon 57: 983. 2008. Sweetia panamensis Benth., J. Linn. Soc., Bot. 8: 263. 1865. Acosmium panamense (Benth.) Yakovlev, Notes Roy. Bot. Gard. Edinburgh 29: 353. 1969. Tipo: Panamá, Paraiso Station, S. Hayes 267 (Holótipo K [foto K 000500776!, foto neg. 2807 NY!]). Fig. 4A-I, 7A

Árvore (8-)10-40 m alt., tronco reto, ritidoma castanho escuro, quase liso, com pequenas fissuras longitudinais, ramos glabros, os mais jovens pubérulos. Folha imparipinada, raro paripinada, 7-13(-15) folíolos, pecíolo 1,5-3 cm compr., raque foliar 5,5-14 cm compr., ambos pubérulos a glabros; pulvínulo 2-4 mm compr.; folíolo 3,8-9 x 1-3,5 cm, concolor, ovado, lanceolado a elíptico, face adaxial glabra, abaxial glabrescente, base obtusa, arredondada a cuneada, ápice emarginado a acuminado. Inflorescência com eixo pubérulo, racemos $8-14 \mathrm{~cm}$ compr.; bráctea 1,2-1,5 $\mathrm{mm}$ compr., bractéolas 0,8-1,1 mm compr. Flor 6,5-8 $\mathrm{mm}$ compr; pedicelo 1-2 mm compr.; hipanto 1,2-1,4 $\mathrm{mm}$ compr.; cálice pubérulo, tubo 1-1,3 mm compr., lacínios 1,9-2,2 mm compr.; corola glabra, pétala adaxial 4-5 x 2-3 mm, oblata, ápice emarginado, raro truncado, demais pétalas 5,8-6,3 $\mathrm{x}$ 2,4-3 mm, obovadas, ápice emarginado, raro arredondado; filetes 6,5-7,5 mm compr., anteras 0,5-0,7 mm compr.; ovário glabro, 3 ou 4 óvulos, estípite 1,5-2 mm compr. Legume sa- 


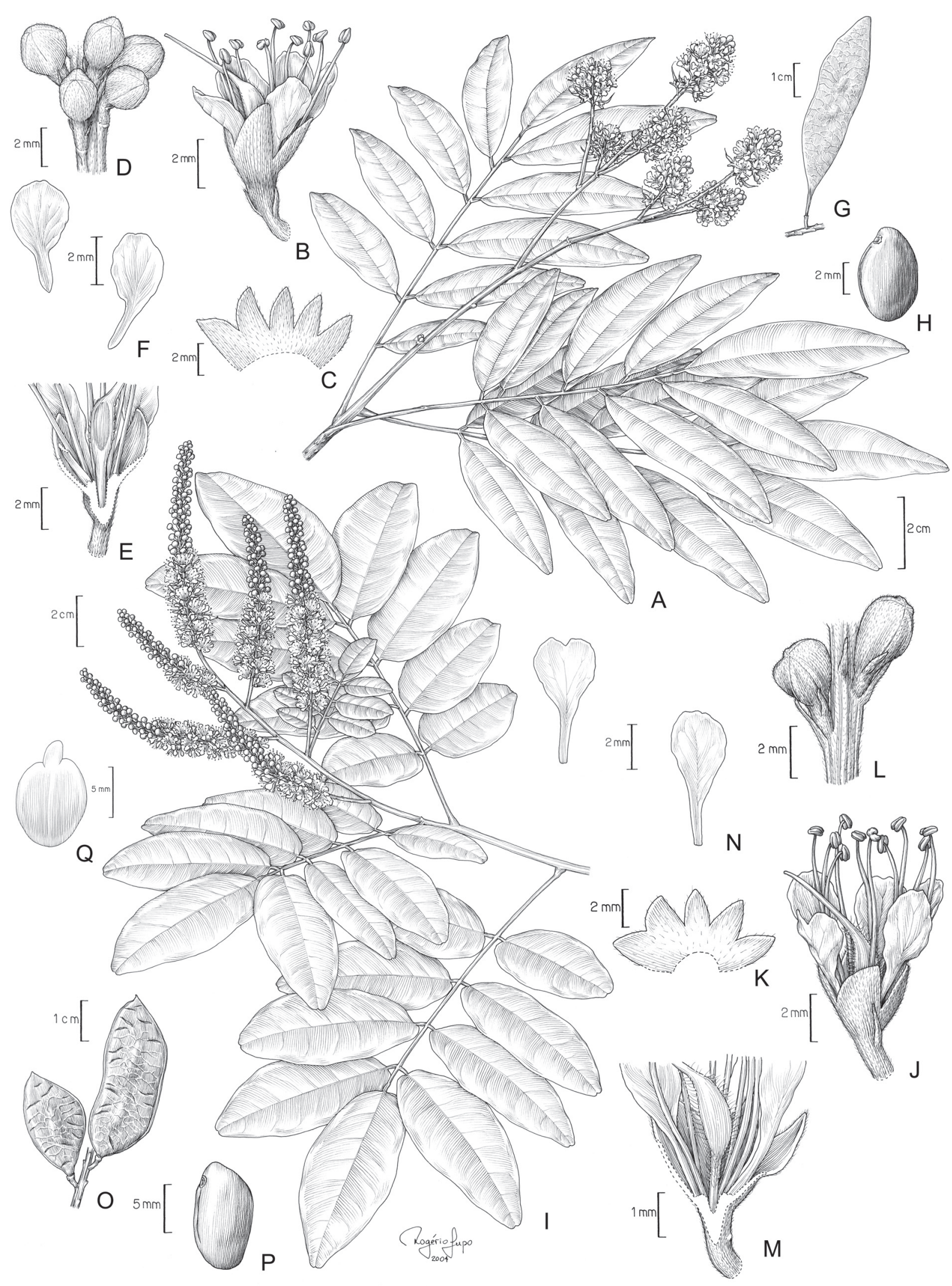

Figura 3. A-H. Leptolobium glaziovianum (Harms) Sch. Rodr. \& A.M.G. Azevedo. A. Ramo com flores. B. Flor. C. Cálice. D. Botões florais. E. Corte longitudinal da flor. F. Pétalas adaxial (acima) e pétala lateral. G. Fruto. H. Semente. I-Q. Leptolobium nitens Vogel. I. Ramo com flores. J. Flor. K. Cálice. L. Botões florais. M. Corte longitudinal da flor. N. Pétalas adaxial (acima) e pétala lateral. O. Frutos. P. Semente. Q. Embrião (A-F: Badini s.n. [RB 202692]; G-H: Caetano 25; I: Ducke 458; J-N: Davidse et al. 27897; O-P: Black 49-7993; Q: Faria \& Silva 621). 
maroide, 4,5-9 x 1,2-2 cm, glabro, ala sutural ausente, estípite 2-5 mm compr., 1-4 sementes. Semente 5,5-7 x 4,8-6 x 2-2,7 $\mathrm{mm}$, ovado-elíptica, hilo 0,9-1,1 x 0,5-0,6 mm, elíptico; eixo hipocótilo-radícula paralelo ou levemente oblíquo.

Material selecionado: BELIZE. Boundary of Cayo-Stann Creek Districts, 13/VIII/1975, fl., Dwyer \& Dieckman 13038 (U). COLÔMBIA. Atlântico: entre Sabanalarga y Cascajal, 24/VII/1955, fl., Dugand 4950 (COL). COSTA RICA. Guanacaste, Liberia, 30/XI/1995, fr. imat., Pennington et al. 619 (NY). San Jose, ciudad Colon, 06/VII/1983, fl., Barringer 3654 (HBG). GUATEMALA. Petén, 09/X/1971, fl., Ortíz 1995 (MICH). Alto Verapaz: Panzós, 18/VII/1988, fl., Martinéz et al. 22848 (NY). MÉXICO. Chiapas: Ocosingo, 16/VIII/1984, fl., Martínez 7307 (L). México: Chapingo, 02/ XII/1967, fr., Pennington \& Sarukhán 9387 (NY). Oaxaca: Temascal, 13/III/1989, fr., Hughes 1308 (NY, RB). Tabasco: Naranjito, 12/XI/1975, fr., Menendez et al. 264 (B). Vera Cruz: San Pedro Zoteapan, 07/VIII/1985, fl., Trigos 3340 (NY). VENEZUELA. Zulia: Perijá, 11/X/1979, fl., Bunting \& Arboleda 8101 (VEN).

Ocorre desde o México até a Colômbia e Venezuela, geralmente em florestas tropicais perenifólias. Coletada com flores de fevereiro a abril e de julho a outubro e com frutos de outubro a maio. Conhecida como chichipate, quina-silvestre (Guatemala), guayacán, bálsamo-amarillo, amargoso (México) e vera-de-agua (Venezuela). Utilizada pela madeira (Pauwells et al. 1999) e como medicinal (Wiedenfeld \& Andrade-Cetto 2003). Além disso, foi introduzida em alguns países da África tropical, sendo plantada em linhas que funcionam como quebra-fogo (Pauwells et al. 1999). Por outro lado, a casca de L. panamense já foi utilizada nos Estados Unidos da América como uma droga chamada "cascara amarga", para o tratamento contra sífilis, afecções cutâneas crônicas, resfriados e anemia (Balandrin \& Kinghorn 1982; Veitch et al. 1997). Em adição, esta planta é usada tradicionalmente no México para o tratamento do diabetes tipo II, sendo que seus extratos hidrofílicos mostraram em ratos de laboratório uma redução estatisticamente significante nos níveis de glicose do sangue (Wiedenfeld \& Andrade-Cetto 2003).

Leptolobium panamense apresenta a distribuição mais setentrional dentre as espécies do gênero. É vegetativamente similar a L. elegans. Contudo, os pulvínulos menores, e principalmente, a pétala adaxial diferenciada em $L$. panamense podem distingui-la de L. elegans. Além disso, L. panamense assemelha-se a $L$. araguaiense e $L$. stirtonii (ver discussão nestas espécies).

10. Leptolobium parvifolium (Harms) Sch. Rodr. \& A.M.G. Azevedo, Taxon 57: 983. 2008. Sweetia parvifolia Harms, Bot. Jahrb. Syst. 42: 211. 1909. Acosmium parvifolium (Harms) Yakovlev, Notes Roy. Bot. Gard. Edinburgh 29: 353. 1969. Tipo: Brasil, Piauí, Serra Branca, E. Ule 7156 (Lectótipo HBG!, designado por Rodrigues \& Tozzi 2008b; Isolectótipos K [foto K000188426!], L!).

Fig. $4 \mathrm{~J}-\mathrm{R}, 6 \mathrm{~A}$
Árvore 3-10 m alt., tronco reto, ritidoma liso, cinza, ramos glabros, os mais jovens pubescentes. Folha imparipinada, 5-7(-9) folíolos, pecíolo 0,5-2,2 cm compr., raque foliar 1-4,5 cm compr., ambos glabros a pubescentes; pulvínulo 0,8-3 mm compr.; folíolo $0,8-6 \times$ x 0,7-2,8 cm, concolor, ovado ou orbicular, glabro em ambas as faces, exceto na face abaxial por tricomas escassos junto à nervura principal e margens, base arredondada a cordada, ápice emarginado. Inflorescência com eixo pubescente a tomentoso, racemos 3-9 cm compr.; brácteas 1,6-2,5 mm compr., bractéolas 1-1,5 mm compr. Flor 7-10 mm compr.; pedicelo 1,7-2,5 mm compr.; hipanto 1,4-2,3 mm compr.; cálice pubescente, tubo 1,1-1,7 mm compr., lacínios 1,7-2,5 mm compr.; corola glabra, pétala adaxial 5,7-6,1 x 3,2-3,8 mm, oblata, ápice emarginado, demais pétalas 6,1-7 x 1,8-3,3 mm, obovadas, ápice arredondado; filetes 5-7,5 mm compr., anteras 0,6-1 mm compr.; ovário glabro a glabrescente, ciliado nas margens, 4-6 óvulos, estípite 1,5-2,3 mm compr. Legume samaroide 3-6 x 1,2-1,8 cm, glabro, ala sutural ausente, estípite 4,5-6 mm compr., 1-2 sementes. Semente 5,5 x 4,5 x 1,5-2,5 $\mathrm{mm}$, oblongo-elíptica, hilo ca. 0,6 x 0,6 mm, circular; eixo hipocótilo-radícula paralelo.

Material selecionado: BRASIL. Ceará: s.loc., entre São José do Belmonte e Jati, 13/V/1971, fl., Heringer et al. 752 (F, RB, UB). Piauí: Pedro II, 06/IV/2002, fr., Rodrigues et al. 1498 (MIRR, UEC); s.loc., Serra Branca, fl., I.1907, Ule 7433 (HBG).

Ocorre somente no Brasil (Piauí e Ceará), no Bioma Caatinga e em áreas de transição com o Bioma Cerrado, em vegetação arbóreo-arbustiva baixa sobre afloramentos rochosos. Coletada com flores em janeiro, março e maio e com frutos em abril.

Leptolobium parvifolium é semelhante a L. dasycarpum, mas pode ser distinta pelo menor comprimento dos pecíolos, pelas brácteas e bractéolas menores, pela pétala adaxial diferenciada e pelo ovário glabro, exceto por tricomas esparsos nas margens. Além disso, o tronco reto, liso e cinza de L. parvifolium é outro caráter útil para diferenciá-la de L. dasycarpum, que apresenta tronco muitas vezes tortuoso, suberoso e marrom-acinzentado.

11. Leptolobium stirtonii (Aymard \& V. González) Sch. Rodr. \& A.M.G. Azevedo, Taxon 57: 983. 2008. Acosmium stirtonii Aymard \& V. González, Harvard Pap. Bot. 7: 399. 2003. Tipo: Venezuela, Amazonas, município Atures, J.A. Steyermark et al. 131496 (Holótipo VEN; Isótipos $\mathrm{F} !, \mathrm{MO}, \mathrm{NY}$ !).

Fig. 5A-I, 7B

Árvore ou arvoreta 5-25 m alt., ritidoma castanho ou cinza, com fissuras longitudinais, ramos glabros ou esparsamente pubescentes. Folha imparipinada, raro paripinada, 5-7 folíolos, pecíolo 1,8-4 cm compr., raque foliar 1,8-4,5(7) $\mathrm{cm}$ compr., ambos glabros a esparsamente pubescentes; pulvínulo 3-5 mm compr.; folíolo 3,5-6 x 1,4-3,8 cm, concolor, ovado a elíptico, glabro em ambas as faces, base 


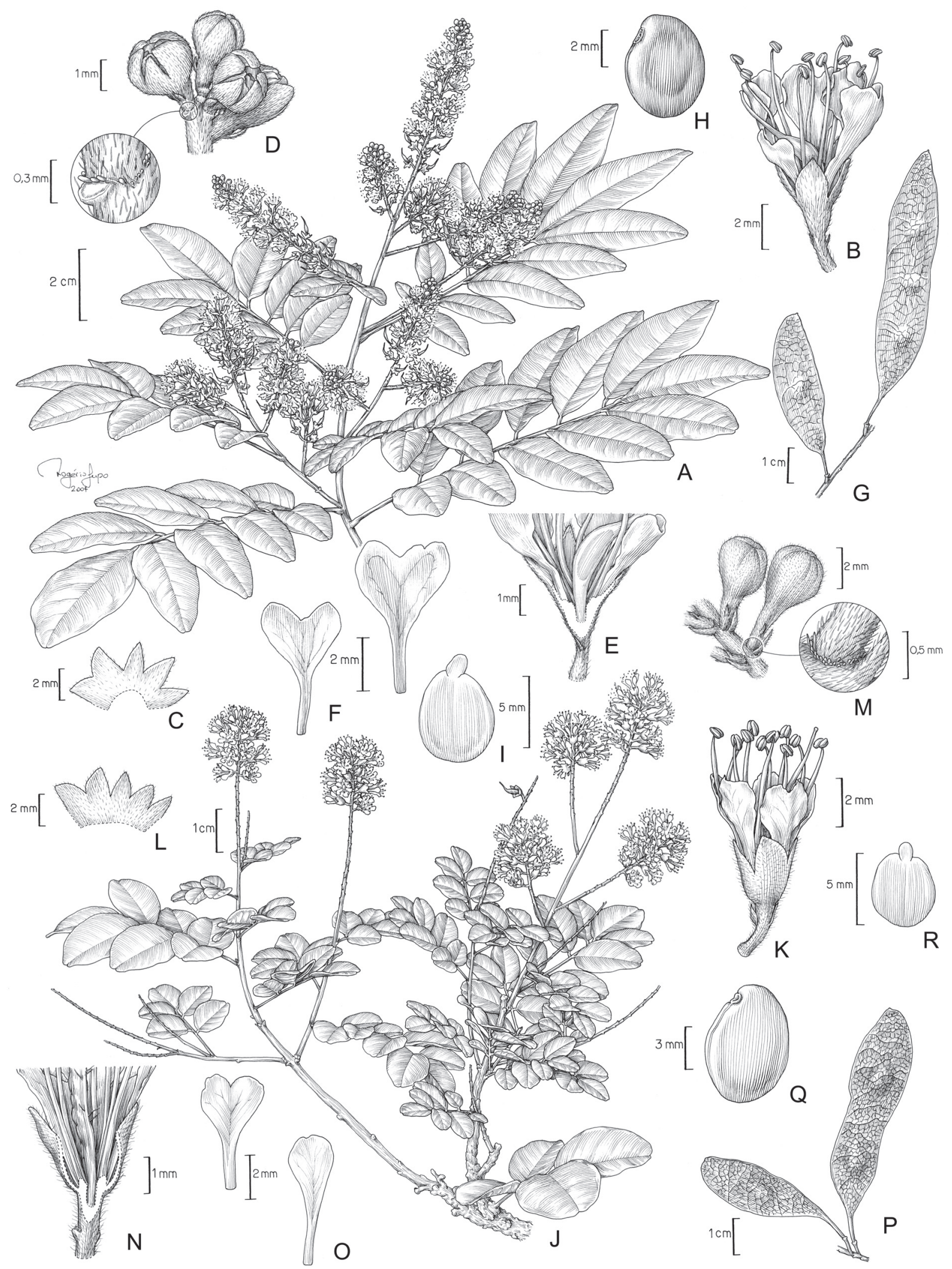

Figura 4. A-I. Leptolobium panamense (Benth.) Sch. Rodr. \& A.M.G. Azevedo. A. Ramo com flores. B. Flor. C. Cálice. D. Botões florais, com glândulas na inserção do pedicelo. E. Corte longitudinal da flor. F. Pétalas lateral (acima) e adaxial. G. Frutos. H. Semente. I. Embrião. J-R. Leptolobium parvifolium (Harms) Sch. Rodr. \& A.M.G. Azevedo. J. Ramo com flores. K. Flor. L. Cálice. M. Botões florais, com glândulas na inserção do pedicelo. N. Corte longitudinal da flor. O. Pétalas adaxial (acima) e lateral. P. Frutos. Q. Semente. R. Embrião (A-B, E-F: Dugand 4950; C: Bunting \& Arboleda 8101; D: Trigos 3340; G-I: Hughes 1308; J-O: Ule 7156; P-R: Rodrigues et al. 1498). 
cordada a arredondada, ápice emarginado. Inflorescência com eixo glabro a esparsamente pubescente, racemos 7-12 cm compr.; bráctea 2-3,8 $\mathrm{mm}$ compr., bractéolas 1,5-2,5 mm compr. Flor 6-8 mm compr.; pedicelo 1,5-2,2 $\mathrm{mm}$ compr.; hipanto 1,1-1,3 mm compr.; cálice pubescente, tubo 0,7-1,1 mm compr., lacínios 2-2,7 mm compr.; corola glabra, pétala adaxial 3,2-5 x 2,4-3,5 mm, oblata a largamente obovada, ápice emarginado, raro arredondado, demais pétalas 4,2-7 x 2-3 mm, obovadas, ápice arredondado; filetes $6-8 \mathrm{~mm}$ compr., anteras $0,6-0,8 \mathrm{~mm}$ compr.; ovário pubescente, 4 óvulos, estípite 1,5-2,5 mm compr. Legume samaroide 2,8-6 x 1,6-2 cm, glabro, ala sutural 0,5-1 mm larg., estípite 5-9 mm compr., 1-3 sementes. Semente 5-6 x 4-5 x 3-3,5 mm, suborbicular a ovada, hilo ca. $0,7 \times 0,7 \mathrm{~mm}$, circular; eixo hipocótilo-radícula paralelo.

Material selecionado: BRASIL. Roraima: Amajari, 23/ II/1967, fl., Prance et al. 4605 (INPA, MG, NY, R); ibid., 14/ VII/1986, fl., Henderson \& Lima 593 (INPA, NY); s.loc., ramal ao sul do rio Surumu, 07/IX/1993, fr., Sanaiotti 224 (INPA, MIRR, UB). GUIANA. Essequibo: Sand Creek Village, 22/VI/1989, fl., Gillespie et al. 1768 (INPA, MG, NY, RB). VENEZUELA. Bolívar: Cedeño, 15/X/1985, fr., Boom \& Grillo 6381 (COL, INPA, NY); Sucre, 06/V/1997, fl., Knab-Vispo et al. 675 (NY); s.loc., próx. caserío Los Rosos, 1-25/VIII/1965, fl., Blanco 246 (NY).

Ocorre na Venezuela, Guiana e Brasil (Roraima) no Bioma Amazônia, em savanas, às vezes sobre afloramentos rochosos, matas semidecíduas ou borda de matas ripárias. Coletada com flores de maio a agosto e com frutos de setembro a outubro. Conhecida como darora e walaweri (Brasil), congrio-piedrero e karamate 'yo' (Venezuela).

Esta espécie é similar a L. elegans, da qual pode ser distinta pela pétala adaxial diferenciada e maior diâmetro das sementes. Pode ser distinguida de L. panamense pelo menor número de folíolos, maior comprimento das bractéolas e cálice e maior diâmetro das sementes.

12. Leptolobium tenuifolium Vogel, Linnaea 11:391. 1837. Sweetia tenuifolia (Vogel) Benth. in Mart., Fl. Bras. 15(2): 7. 1870. Acosmium tenuifolium (Vogel) Yakovlev, Notes Royal Bot. Gard. Edinburgh 29: 353. 1969. Tipo: Brasil, "inter Campos et Victoria", s.d., F. Sellow s.n. (Holótipo B destruído [foto neg. 1876 F!, NY!]; isótipo F 621389! [fragmento]).

Fig. 5J-R, 7B

Árvore ou arvoreta 5-25 m alt., ritidoma castanho ou cinza, com fissuras longitudinais, ramos glabros ou esparsamente pubescentes. Folha imparipinada, raro paripinada, 5-9 folíolos, pecíolo 1,8-4,5 cm compr., raque foliar $3-12 \mathrm{~cm}$ compr., ambos glabros a esparsamente pubescentes; pulvínulo 2,5-4 mm compr.; folíolo 3,2-9 x 1,8-6 cm, concolor, ovado, lanceolado a elíptico, glabro em ambas as faces, base cuneada, obtusa cordada, ápice emarginado. Inflorescência com eixo glabro a esparsamente pubescente, racemos 5-10 cm compr.; bráctea 2-2,7 mm compr., bractéolas 1,2-1,8 mm compr. Flor 8-9 mm compr.; pedicelo 1,5-2,2 mm compr.; hipanto 1-1,3 mm compr.; cálice pubescente, tubo ca. $1 \mathrm{~mm}$ compr., lacínios 2-2,3 mm compr.; corola glabra, pétala adaxial 4,5-5,2 x 2-3 mm, oblata a largamente obovada, ápice emarginado ou arredondado, demais pétalas 5,5-6,2 x 1,8-2,7 mm, obovadas, ápice arredondado; filetes 7-8 mm compr., anteras $0,6-0,8 \mathrm{~mm}$ compr.; ovário glabro a glabrescente, 4 óvulos, estípite 1,8-2,1 mm compr. Legume samaroide 3-7 x 1,7-2,2 cm, ala sutural ausente, estípite 2,55,5 mm compr., 1-3 sementes. Semente 7,2-10 x 5-8 x 2,7-3 $\mathrm{mm}$, elíptica a ovada, hilo 1,4-1,5 x 0,9-1 mm, elíptico; eixo hipocótilo-radícula paralelo.

Material selecionado: BRASIL. Bahia: Ilhéus, 17/ IV/1986, fr., Mattos Silva et al. 2052 (RB); S.loc, vale do rio Mucurí, 13/VII/1968, fr., Belém 3857 (F). Espírito Santo: Linhares, 05/VII/1990, fr., Menandro 203 (CVRD); ibid., Lagoa do Durão, 12/IV/1934, fl., Kuhlmann 175 (RB); ibid., 14/IV/1934, fr., Kuhlmann 208 (RB). Rio de Janeiro: Campos, 19/IX/1978, fr., Vianna et al. 1360 (RB).

Ocorre somente no Brasil (Rio de Janeiro, Espírito Santo e Bahia), no Bioma Mata Atlântica, em matas ripárias, vegetação alterada, bordas de manguezais e de matas de restinga. Coletada com flores em abril e com frutos em abril, julho e setembro. Conhecida como juruna e sucupirada-beira-d'água.

Esta espécie é similar vegetativamente a $L$. elegans, da qual pode ser distinta pelos pulvínulos geralmente menores e pelo ritidoma não suberoso e pela pétala adaxial diferenciada e frequentemente menor. Além disso, L. tenuifolium destaca-se por apresentar sementes relativamente grandes, o que a distingue de todas as espécies de Leptolobium com frutos samaroides.

No isótipo de L. tenuifolium, foram encontradas folhas membranáceas, às quais se refere o epíteto específico. Contudo, elas provavelmente representam folhas jovens, pois as demais coletas, bem como observações de campo (Rodrigues et al. 1603), mostraram que esta espécie é caracterizada por folhas coriáceas. Neste trabalho, não foi designado lectótipo para L. tenuifolium, em razão da natureza fragmentada do único isótipo analisado pelos autores, proveniente do herbário $\mathrm{F}$.

\section{Nomes excluídos de Leptolobium}

Leptolobium aurantiacum Mart., Herb. Fl. Bras. n. 1149. cat. aut. Segundo Bentham (1870), corresponde a Diptychandra aurantiaca Tul., Ann. Sci. Nat., Bot. sér. 2, 20: 139. 1843.

Leptolobium clandestinum (J.C. Wendl.) Benth. Comm. Legum. Gen.: 61. 1837. Sinônimo nomenclatural de Glycine clandestina J.C. Wendl., Bot. Beob. 54. 1798 (Pfeil et al. 2001).

Leptolobium costulatum Miq., Stirp. Surinam. Select.: 17. 1851. Basiônimo de Ormosia costulata (Miq.) Kleinhoonte, Recueil Trav. Bot. Néerl. 22: 392. 1926 (Rudd 1965). 


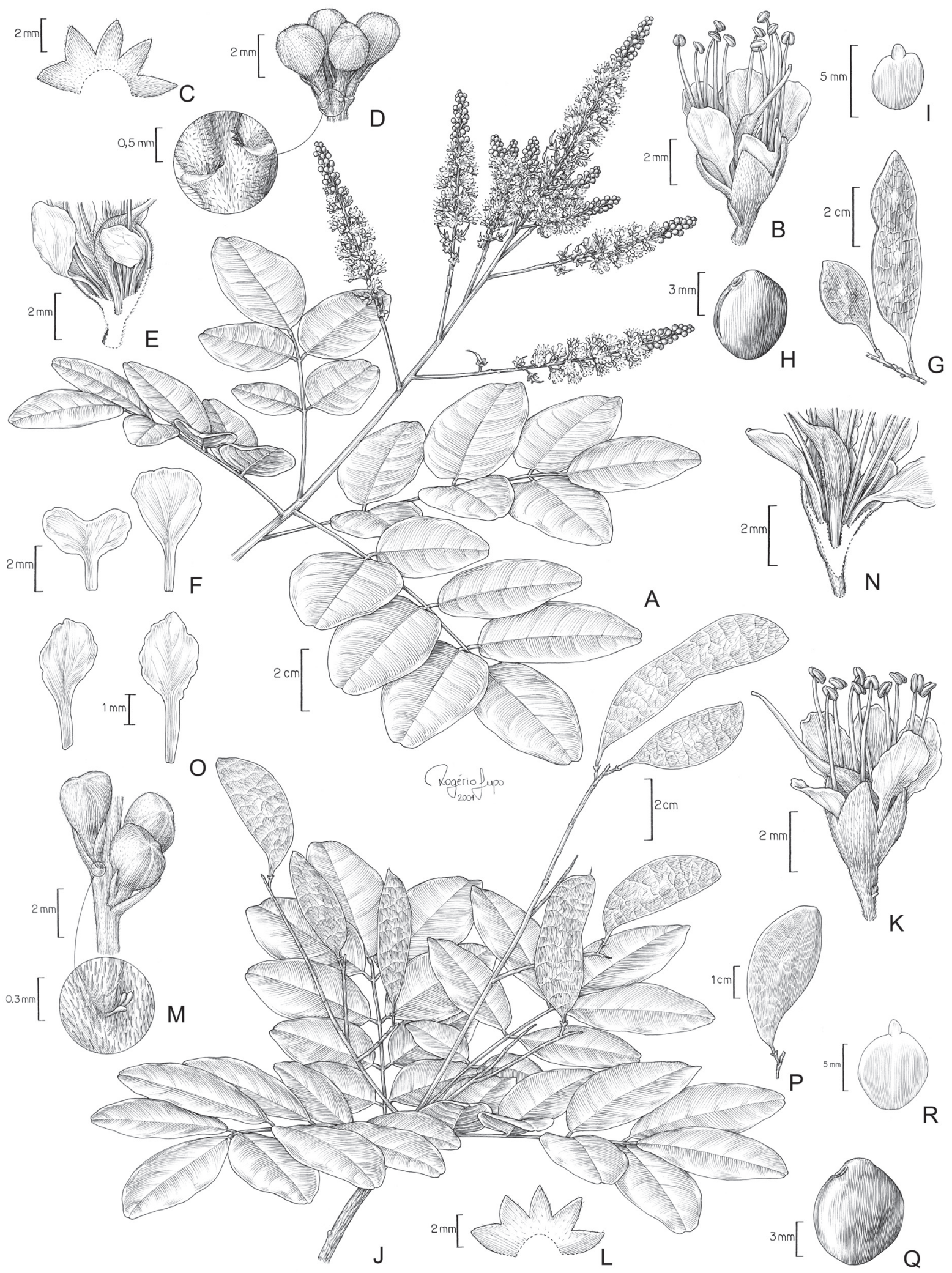

Figura 5. A-I. Leptolobium stirtonii (Aymard \& V. González) Sch. Rodr. \& A.M.G. Azevedo. A. Ramo com flores. B. Flor. C. Cálice. D. Botões florais, com glândulas na inserção do pedicelo. E. Corte longitudinal da flor. F. Pétalas adaxial (esquerda) e lateral. G. Frutos. H. Semente. I. Embrião. J-R. Leptolobium tenuifolium Vogel. J. Ramo com frutos. K. Flor. L. Cálice. M. Botões florais, com glândulas na inserção do pedicelo. N. Corte longitudinal da flor. O. Pétalas adaxial (esquerda) e lateral. P. Fruto. Q. Semente. R. Embrião (A: Prance et al. 4605; B, E-F: Henderson \& Lima 593; C-D: Blanco 246; G-H: Knab-Vispo et al. 675, NY; I: Steyermark et al. 131496; J: Mattos Silva et al. 2052; K-O: Kuhlmann 175; P-Q: Belém 3857; R: Kuhlmann 2080). 

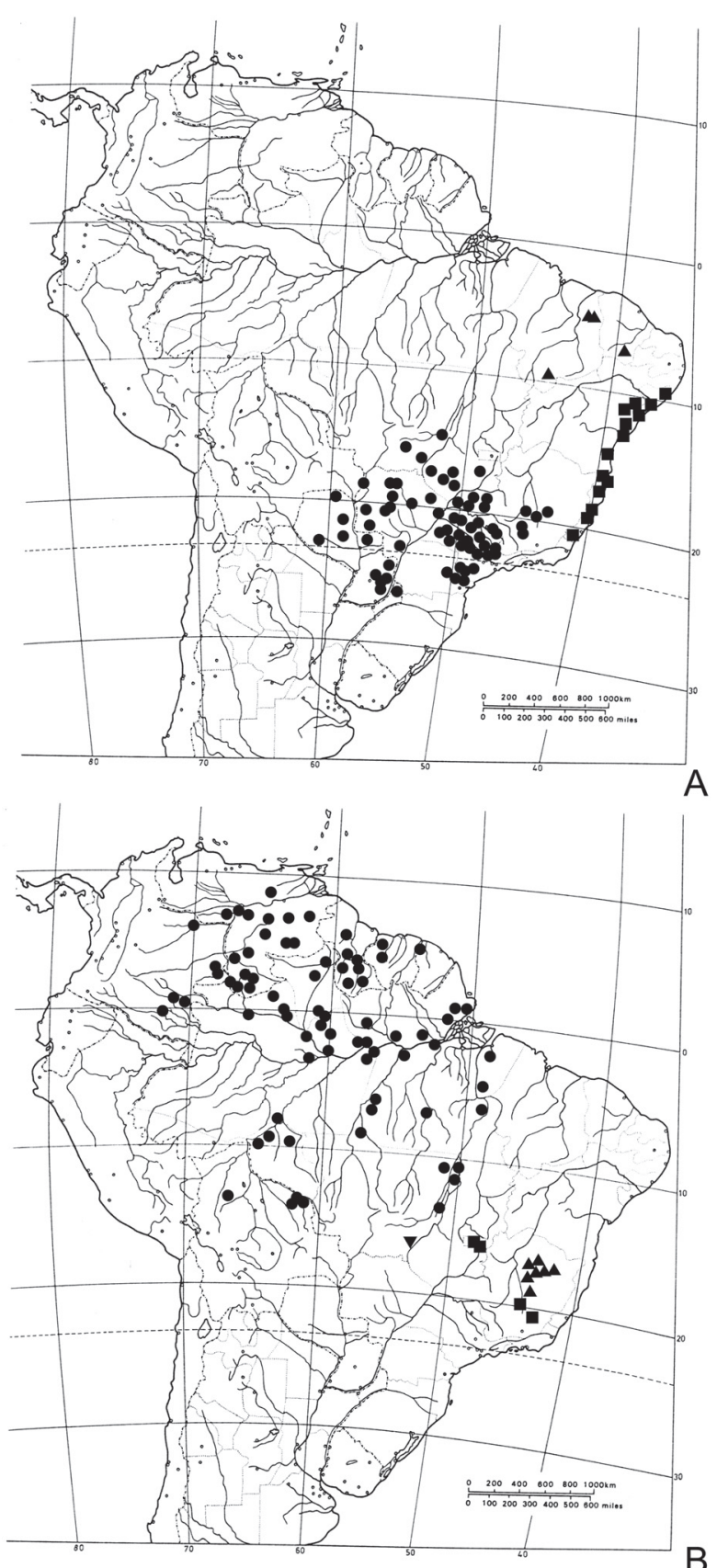

Figura 6. Mapas de distribuição geográfica de espécies de Leptolobium Vogel (Leguminosae Papilionoideae). A. L. bijugum (Spreng.) Vogel (quadrados), L. elegans Vogel (ćrculos) e L. parvifolium (Harms) Sch. Rodr. \& A.M.G. Azevedo (triângulos); B. L. brachystachyum (Benth.) Sch. Rodr. \& A.M.G. Azevedo (triângulos), L. glaziovianum (Harms) Sch. Rodr. \& A.M.G. Azevedo (quadrados), L. nitens Vogel (círculos) e L. multijugum Sch. Rodr. \& A.M.G. Azevedo (triângulo invertido).

Leptolobium elongatum Benth., Comm. Legum. Gen.: 61. 1837. Sinônimo taxonômico de Glycine tabacina (Labill.) Benth., Fl. Austral. 2: 244. 1864 (Ren \& Gilbert 2010).

Leptolobium leiocarpum Vogel, Linnaea 11: 393. 1837. Basiônimo de Apuleia leiocarpa (Vogel) J.F. Macbr. Contr. Gray Herb. 59: 23. 1919 (Sousa et al. 2010).
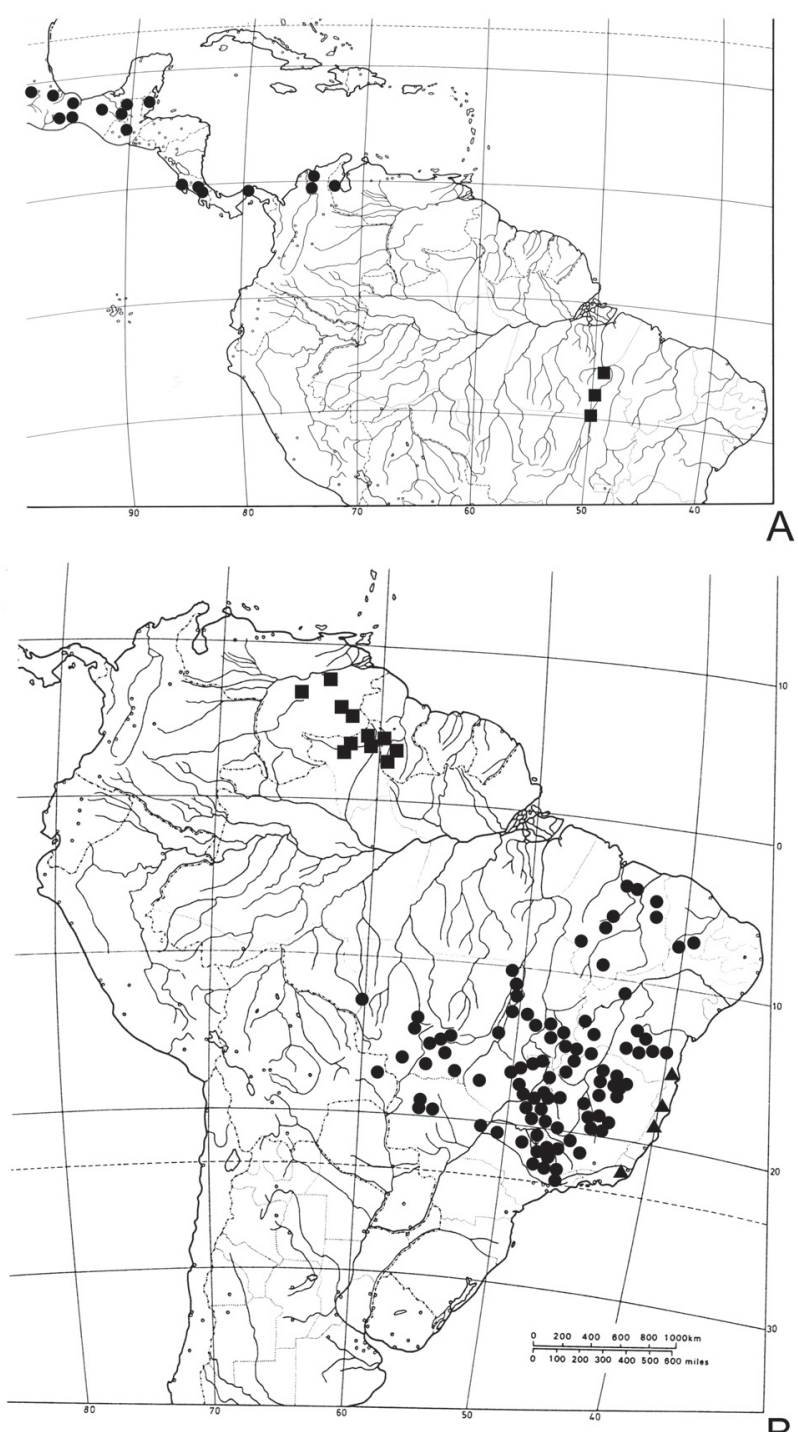

Figura 7. Mapas de distribuição geográfica de espécies de Leptolobium Vogel (Leguminosae Papilionoideae). A. L. araguaiense Sch. Rodr. \& A.M.G. Azevedo (quadrados), L. panamense (Benth.) Sch. Rodr. \& A.M.G. Azevedo (círculos); B. L. dasycarpum Vogel (círculos), L. stirtonii (Aymard \& V. González) Sch. Rodr. \& A.M.G. Azevedo (quadrados) e L. tenuifolium Vogel. (triângulos).

Leptolobium luteum Mart., Herb. Fl. Bras. n. 1148. cat. aut. Corresponde a Tachigali aurea Tul., Arch. Mus. Hist. Nat. 4: 169. 1844 (Bentham 1870).

Leptolobium microphyllum Benth., Comm. Legum. Gen.: 61. 1837. Sinônimo taxonômico de Glycine clandestina J.C. Wendl., Bot. Beob. 54. 1798. (Pfeil et al. 2001).

Leptolobium paradisi Cortés. Fl. Colombia (Cortes) 142. 1897, nom. nud.

Leptolobium punctatum Benth., Linnaea 22: 526. 1849. Sinônimo taxonômico de Myrocarpus frondosus Allemão, Diss. Leg.: 22, com ícone, 1848 (Sartori \& Tozzi 2004). 
Leptolobium tabacinum (Labill.) Benth. , Comm. Legum. Gen.: 61. 1837. Sinônimo nomenclatural de Glycine tabacina (Labill.) Benth., Fl. Austral. 2: 244. 1864 (Ren \& Gilbert 2010).

Leptolobium tomentosum Benth., Comm. Legum. Gen.: 61. 1837. Sinônimo taxonômico de Glycine tomentella Hayata, Icon. Pl. Formosan. 9: 29. 1920 (Ren \& Gilbert 2010).

\section{Agradecimentos}

Agradecemos à Dra. Andréia S. Flores pelo seu apoio ao longo deste trabalho; ao Rogério Lupo pelas ilustrações botânicas; aos curadores dos herbários citados pelo acesso às coleções; aos dois assessores anônimos pelas correções e sugestões; à FAPESP (proc. 00/09429-0), pela bolsa de doutorado concedida a RSR, que também agradece aos colegas, professores e técnicos do PPG em Biologia Vegetal da Unicamp.

\section{Referências}

Aymard, G.A. \& González, V. 2003. A new species of Acosmium (Leguminosae: Papilionoideae, Sophoreae). Harvard Papers in Botany 7: 399-402.

Balandrin, M.F. \& Kinghorn, D. 1982. (-)-4 $\alpha$-hydroxysparteine, a new natural product from Acosmium panamense. Heterocycles 19: 1931-1934.

Barroso, G.M.; Morim, M.P.; Peixoto, A.L. \& Ichaso, C.L.F. 1999. Frutos e sementes: morfologia aplicada à sistemática de dicotiledôneas. Viçosa, UFV.

Bentham, G. 1865. On the genera Sweetia, Sprengel, and Glycine, Linn., simultaneously published under the name of Leptolobium. Journal of the Linnean Society, Botany 8: 259-267.

Bentham, G. 1870. Leguminosae II: Swartzieae et Caesalpinieae. Pp. 1-259. In: Martius, C.F.P. \& Eichler, A. (eds.). Flora brasiliensis. Vol. 15, part 2. Lipsiae, F. Fleischer.

Bridgewater, S.G.M. \& Stirton, C.H. 1997. A morphological and biogeographic study of the Acosmium dasycarpum complex (Leguminosae: Papilionoideae, Sophoreae). Kew Bulletin 52: 471-475.

Font Quer, P. 1979. Diccionario de botánica. Barcelona, Editorial Labor. Lorenzi, H. 1992. Árvores brasileiras. Nova Odessa, Plantarum.

Mohlenbrock, R.H. 1963. A revision of the leguminous genus Sweetia. Webbia 17: 223-263.

Pauwells, L.; Breyne, H. \& Delaude, C. 1999. Acosmium panamense (Fabaceae), arbre intéressant introduit en Afrique tropicale. Systematics and Geography of Plants 69: 3-7.

Pennington, R.T.; Lavin, M.; Ireland, H.; Klitgaard, B.; Preston, J. \& Hu, J-M. 2001. Phylogenetic relationships of basal Papilionoideae legumes based upon sequences of the chloroplast trnL intron. Systematic Botany 26: 537-556.

Pfeil, B.E.; Tindale, M.D. \& Craven, L.A. 2001. A review of the Glycine clandestina species complex (Fabaceae: Phaseolae) reveals two new species. Australian Systematic Botany 14:891-900.

Pott, A. \& Pott, V.J. 1994. Plantas do pantanal. Corumbá, Embrapa-CPAP. Radford, A.E.; Dickison, W.C.; Massey, J.R. \& Bell, C.R. 1974. Vascular plant systematics. New York, Harper \& Row.

Ren, S. \& Gilbert, M.G. 2010. Glycine. Pp.250-252. In: Flora of China Editorial Committee (Eds.). Flora of China. Vol. 10, Fabaceae. Beijing, Missouri Botanical Garden Press and Science Press.

Rodrigues, R.S. \& Tozzi, A.M.G.A. 2006. Guianodendron, a new genus of Leguminosae (Papilionoideae) from South America. Novon 16: 129-132.

Rodrigues, R.S. \& Tozzi, A.M.G.A. 2007a. Morphological analysis and re-examination of the taxonomic circumscription of Acosmium (Leguminosae, Papilionoideae, Sophoreae). Taxon 56: 439-452.

Rodrigues, R.S. \& Tozzi, A.M.G.A. 2007b. Morfologia de plântulas de cinco leguminosas genistóides arbóreas do Brasil (LeguminosaePapilionoideae). Acta Botanica Brasilica 21: 599-607.

Rodrigues, R.S. \& Tozzi, A.M.G.A. 2008a. Systematic relevance of seedling morphology in Acosmium, Guianodendron, and Leptolobium (Leguminosae, Papilionoideae). Brittonia 60: 287-296.

Rodrigues, R.S. \& Tozzi, A.M.G.A. 2008b. Reinstatement of the name Leptolobium Vogel (Leguminosae, Papilionoideae, Sophoreae). Taxon 57: 980-984.

Rodrigues, R.S. \& Tozzi, A.M.G.A. 2009. Revisão taxonômica de Acosmium Schott (Leguminosae, Papilionoideae, Sophoreae. Acta Botanica Brasilica 23: 164-174.

Rodrigues, R.S. \& Tozzi, A.M.G.A. 2010. Two new species of Leptolobium (Leguminosae, Papilionoideae) from Brazil. Brittonia 62: 20-25.

Rudd, V.E. 1965. The American species of Ormosia (Leguminosae). Contributions from the United States National Herbarium 32: 279-384.

Sartori, A.L.B \& Tozzi, A.M.G.A. 2004. Revisão taxonômica de Myrocarpus Allemão (Leguminosae, Papilionoideae, Sophoreae. Acta Botanica Brasilica 18: 521-535.

Sousa, F.P.S.T.; Lewis, G.P. \& Hawkins, J.A. 2010. A revision of the South American genus Apuleia (Leguminosae, Cassieae). Kew Bulletin 65: $225-232$

Stearn, W.T. 1992. Botanical Latin. London, David \& Charles Book.

Thiers, B. 2011. Index Herbariorum: a global directory of public herbaria and associated staff. New York Botanical Garden's Virtual Herbarium. http://sweetgum.nybg.org/ih/ (Acesso em 14/09/2011).

Veitch, N.C.; Goodwin, B.L.; Kite, G.C. \& Simmonds, M.S.J. 1997. Methoxylated quinolizidine alkaloids from Acosmium panamense. Phytochemistry 45:847-850.

Vogel, T. 1837. Caesalpinieis Brasiliae. Linnaea 11: 381-416.

Wiedenfeld, H. \& Andrade-Cetto, A. 2003. Pyrone glycosides from Acosmium panamense (Benth.) Yacovlev. Zeitschrift für Naturforschung 58: 637-639.

Wojciechowski, M.F.; Lavin, M. \& Sanderson, M.J. 2004. A phylogeny of legumes (Leguminosae) based on analysis of the plastid matK gene resolves many well-supported subclades within the family. American Journal of Botany 91: 1846-1862.

Yakovlev, G.P. 1969. A review of Sweetia and Acosmium. Notes from the Royal Botanic Garden Edinburgh 29: 347-355. 


\section{Lista de exsicatas}

Acevedo-Rodriguez, P. 8062 (8). Aguillar H., M. 311 (9). Albuquerque, B.W.P. 156, 176 (8). Alencar, M.E. 476 (4). Almeida, E.F. 259 (4). Almeida, S.P. 290 (4). Almeida, S.S. 202, 226 (8). Alvarenga, D. 147, 896,1056 (4). Amaral Jr., A. 81, 93 (5). Amorim, A.M.A. 1535 (2). Anderson, W.R. 6975 (4), 7290, 7627, 8757 (4), 8892 (3), 9052 (4), 10822, 11006 (8), 11519 (4), 11584 (3), 36700 (4). Andrade, A.C.S. 102 (8). Antonialli, A.L. 24 (5). Aragaki, S. 216 (4), 223 (4). Arantes, A.A. 64 (4). Araújo, G.M. FEEP 418 (4). Árbocz, G. 4578 (8). Aristeguieta, L. 5888 (11). Assis, J.S. 68 (4). Assis, M.C. CFCR 11475 (3). Aymard, G. 6439 (8), 8820 (11). Azevedo, M.L.M 334, 432 (4). Badini, J. s.n. RB 202692 (6). Barreto, M. 82 (4). Barringer, K. 3654 (9). Barros, F. 623 (4). Barroso, G.M. 99 (4). Batalha, M.214, 235 (5), 268, 413, 414 (4). Bautista, H.P. 1561 (2). Beck, G. 10156 (8). Belém, R.P. 2105, 3085, 3168, 3187, 3213, 3229, 3231 (2), 3857 (12). Bernarcci, L.C. 760 (5), 1869 (4). Bertoncini, A.P. 425 (5). Bicudo, L.R.H. 1685 (5). Black, G.A. 147M (4), 47-1767, 49-7993, 52-14598, 55-18016 (8), 55-18033, 55-18070 (4), 57-19915 (8). Blanchet, B.A. s.n. MG 32191, 3314, 3317 (4). Blanco, C. 246 (11), 700 (8). Boaventura, M. 27 (4). Boom, B. 6381 (11). Borges, H.B.N. 35476 (5). Brade, A.C 17710, 17711 (4). Briceño, E. 24 (11). Bridgewater, S. 51068 (4). Brito, J.A.L. 19 (5). Bucci, F. 77 (4). Bulhões, B. 34 (4). Bunting, G.S. 3605 (8), 8101 (9). Cabral. E. 349 (5). Caetano, V.J. 25 (6). Campbell, D.G. P21986, P22318, P22346, P22421, P21836 (8). Carvalho, A.M. 729 (2), 1823, 2326 (4), 3267 (2). Castellanos, A. 26997 (2). Castillo, A. 5327 (8). Castro, A.J. s.n. TEPB 1054 (10). Castro, A.J. s.n. TEPB 1218 (4). Cavalcante, P. 204, 1715, 1811, 2956 (8). Cavalcanti, T.C. 1164, 1296 (4). Clarke, D. 1379, 2207, 5149 (8). Claussen, P. 232, 312, s.n. BR 842300, s.n. BR 842316 (4). Cobra, L.Q. 112-61 (4). Coelho, F. 565 (8). Coradin, L. 2324 (4). Cordeiro, I. 1057 (5), in CFCR 503, in CFCR 7044 (4). Cordeiro, M.R. 136, 173, 2609, 20/061 (8). Cordovil, S.P. 95 (4). Costa, A.L. s.n. HUEFS 15420 (2). Costa, R.C.M. 251, 316 (8). Cowan, C. 3234 (9). Croizat, L. 75 (8). Cruz, N.D. 6169, 6192 (4). Curran, H.M. 1916 (9). Dambrós, L.A. 156 (8). Dambrós, L.A. 332 (4). Dantas, M. 1424 (8). Davidse, G. 12736, 16840, 27618, 27897 (8). Davis, D.H. 1690 (11). Delascio, F. 11223 (8). Delgado, L. 1258 (8). Dias, A.A. 9 (8), 37 (4). Dias, A.T.G. 5 (8), 471 (8). Dias, B.J. 105 (4). Dias, T.A.B. 35 (4). Diniz, A. s.n. SP 321 (5). Duarte, A.P. 903, 5723, 7980, 9348 (4). Duarte, E.A. 6 (8). Ducke, A. 137, 458, s.n. MG 3720, s.n. MG 8365, s.n. 9005, s.n. MG 10831, s.n. MG 11696, s.n. MG 15291, s.n. MG 15564, s.n. MG 16670, s.n. MG 115875, s.n. RB 11448, s.n. RB 11450, s.n. RB 24053, s.n. RB 280506 (8); Dugand, A. 594 (8), 4950 (9). Dusén, P. 17390 (5). Dwyer, J.D. 13038 (9). Egler, W. 672 (8). Eiten, G. 2591 (4), 3448 (5), 9111, 9421a, 10340 (4). Emmerich, M. 3295 (5). Fanshawe, D.B. in Forest. Dep. 7131 (8). Faria, S.M. 621(8), 1443 (5). Farias, G.L. 435, 436, 532 (2). Farney, C. 1917 (8). Felfili, J. 102, 149 (4). Felippe, G. 203 (5). Ferreira, C.A.C. 1409, 1529, 1585, 2020, 2324 (8), 6057, 6561 (4), 7517, 7646 (8). Ferreira, M.B. 922, 1016 (4). Fiebrig, K. 386 (5). Filgueiras, T.S. 1567 (4). Filho, A.O. 262 (4). Folli, D.A. 573, 835, 879, 1552, 1604, 2160(2). Fonseca, M.L. 1424, 1688 (4). Fontella, J. 2797 (4). Forest Dept. 3452, 7052, 7131 (8). Forzza, R.C. 517 (3). Fróes, R.L. 22241, 22391, 24116 (8), 24759 (1), 25085, 25423, 26117, 26397, 26425, 29072, 29587, 31780, 32306, 33068, 33123, 33208, 33221, 33849 (8), 34063 (4). Furtado, A.P. 28 (5). Ganev, W. 1432 (4). Garcia-Barriga, H. 20896 (8). Gardner, G. 1570 (4). Gentle, P.H. 6848 (9). Gibbs, P.E. 3544 (5), 4171 (4). Gillespie, L.J. 1450 (8), 1768, 1948 (11), 2432 (8). Giulietti, A.M. in CFCR 13568, in CFCR 13615 (4). Glaziou, A.F.M. 12603, 13724 (4), 18207 (6), 19603, s.n. BR 842299, s.n. RB 38387 (4).
Gomes, J.M.L. 2794 (2). Gomes, M. 474 (8). Gómez, L.D. 23905 (9). Gottsberger, G. 11-19186 (8), 32-21186 (5). Goulding, M. 50a, 1184a (8). Gröger, A. 650 (8). Guarino, E.S.G. 504 (4). Guedes, M.L. 3794 (2). Guedes, T.N. 506 (4). Guillén, R. 1886 (8). Guimarães, J.G. 1322, 1366, 1392 (4). Handro, O. 445, 823 (4), s.n. IAC 7378, s.n. UC 964973 (5). Haridasan, M. 348, 421, 218 (4). Harley, R.M. 10864, 11079, 16497 (4), 17952, 18104, 18537 (2), 21291 (4), 24108 (2), in CFCR 6140, in CFCR 6494 (3). Hassler, E. 1359, 1362, 2412, 2982, 3546, 4919, 9624, 12328 (5). Hatschbach, G. 6605, 18900, 20388, 30396, 33156 (5), 33360, 33365, 35335, 37177 (4), 41651 (3), 41695 (4), 44032 (5), 50286 (3), 54636, 55970 (4), 58810, 58845 (5), 61171 (4), 63471 (5), 67167 (3), 67174 (4). Hayes, S. 267 (9). Hensold, N. in CFCR 2837 (3). Henderson, A. 593 (11). Heringer, E.P. 132, 385 (4), 752 (10), 2517 (5), 2679, 2779, 3226, 3524, 5521, 5549, 5647, 8783, 9394, 10654, 12792, 13033, 15297, 17986 (4). Hoehne, F.C. 2615, s.n. SP 20491, s.n. SP 36864, s.n. UEC 84410 (4). Hoehne, W. s.n. SP 321322 (4), s.n. SPF 11653, s.n. SPF 13225 (5), s.n. SPF 14028 (4). Hoffmannsegg, C. s.n. BR 842210 (8). Holst, B.K. 1962 (8). Hostmann, F.W. 1164 (8). Hughes, C.E. 1308 (9). Idrobo, J.M.11365 (8). Irwin, H.S. 6963 (4), 7558 (5), 8341, 8939, 9126, 9869, 13433, 20347 (4), 22728 (3), 22994, 23034 (4), 23451, 23456a, 23519 (3), 23643, 23721, 25712, 25971, 26773, 27030 (4), 28519 (3). JansenJacobs, M.J. 1569, 4600 (8). Janssen, A. 553 (8). Jesus, F.P.R. 104 (4). Jiménez, Q. 1491 (9). Joly, A.B. s.n. SPF 85317 (4). Kallunki, J.A. 418 (2). Kawasaki, M.L. in CFCR 6619 (3). Kinoshita, L.S. 32208 (5). Kirizawa, M. 58, 1348, 1354 (4). Kirkbride Jr., J.H. 4514 (4), 4624 (2), 5027, 5414, 5427 (4). Klein, V.L.G. 487 (2). Knab-Vispo, C. 675 (11). Krapovickas, A. 36287 (4), 46136 (5). Krukoff, B.A. 1470, 5474, 6708 (8). Kubitzki, K. 84-121, 84-170, 84-191, 84-308 (8). Kuhlmann, J.G. 115 (4), 175, 208 (12), 391 (4), 746, 1882 (8), s.n. RB 150028 (5). Kuhlmann, M. 1308 (5). Laboriau, L. 1126 (3). Labouriau, M. 54 (4). Landim, M. 376, 506 (2). Landrum, L.R. 8729 (5). Leitão Filho, H.F. 1400, 1542 (5), 1543 (4), 1570 (5), 1571, 11347, 11728, 11981 (4), 13185 (5). Lewis, G.P. 806, 1010 (2), 1679 (11), in CFCR 7416 (4). Líbano, A.M. 11 (4). Lima, H.C. 966, 1563 (4), 2932, 2939, 2956, 2972, 3850 (2). Lima, H.S. 539 (8). Lima, J.J. s.n. RB 111930 (5). Lima, L.R. 24 (3). Lindeman, J.C. 178 (8). Lisboa, R. 6817 (8). Lobato, L.C.B. 303 (4), 427 (8). Löfgren, A. 529 (5), 1165 (4). Lopes, L.S. 12 (5). Lorenzi, H. s.n. SP 262194 (5). Loureiro, A. s.n. RB 222064 (8). Luetzenburg, P. 1281 (4). Lundell, C.L. 6620, 6831 (9). Luschnath, B. s.n. BR 842317 , s.n. BR 842318 , s.n. BR 842319 , s.n. BR 842320 (2). Maas, P.J.M. 5533, 6576, 7391 (8). Macedo, A. 534 (4), 555 (5). Macedo, M. 1748, 4475 (4). Machado, O. 280 (4). Maciel, U.N. 139, 320 (8). Maestro, A.L. 39, 68 (5). Magalhães, M. 1461, 17174 (4), 18950 (3), s.n. IAN 14434 (4), s.n. IAN 14556 (8). Magaña, M.A. 354 (9). Magnago, H. 331, 364 (4). Maguire, B. 34889, 36190 (8), 44719, 56861 (4). Malme, G.O.A. 2398a (4). Manso, P.S. 253 (5), s.n. BR 842308 (4). Mantovani, W. 789, 1347, 1365, 1576 (4), 12714 (8). Marcondes Ferreira, W. 1000, 1510, 1687 (4). Marimon, B.S. 096-a (5). Marinho, L.R. 381, 419 (8). Markgraf, F. 3146, 3249 (4), 3475 (3). Martens, L.A. 433 (4). Martinelli, G. 6034 (2), 7112, 7339 (8), 11015 (2). Martínez, E. 7307 (9). Martínez, E.M. 22848 (9). MartinezCalderon, G. 1514 (9). Martins, A.B. 68 (4). Martins, F. 1 (5), s.n. SP 22454 (4). Martius, C.F. 1150 (5), 1151 (4). Mattos Silva, L.A. 2052 (12). Mattos, J.R. 8898 (5), 11528, 11539 (4), 14163 (5), 28458 (4). Maury, C.M. 377 (4). McDowell, T. 3400 (8). Meguro, M. in CFCR 8985 (3). Meira Neto, J.A.A. 479 (5). Mello Barreto, H.L. 1229 (4). Mello, F. 25, 5356, 11761 (8). Mello-Silva, R. 1204 (4), 1746, in CFCR 10821 (3). Menandro, M.S. 203 (12). Mendes, I.C.A. 97 (4). Mendonça, R.C. 526, 1548, 2025 (4), 4069 (1). Menendez, F. 264 (10). Mereles, F. 3844 (5). Milliken, W. 378, 2216 (11). Miranda, 
A.M. 3099 (4). Modesto, J.C. 69 (4). Montes, J.E. 27421, 27427 (5). Morais, R.F. 3 (5). Mori, S.A. 11291 (4), 11409a, 11419, 14097, 14176 (2), 20319, 20430, 23644 (8). Morretes, B.L. s.n. SPF 19678 (4). Mota, A.L.P. 792 (4). Nee, M. 41519 (8). Nelson, B.C. 341 (4). Netto, A. 29 (4). Noberto, F. 203 (4). Noblick, L.R. s.n. HUEFS 122 (2). Nóbrega, M.G. 902, 1382, 1426 (4). Nogueira, E. 110 (4). Nogueira, P.E. 691 (8). Nunes, M.S. 18 (5). Nyenhuis, J.J. s.n. FUEL 4281 (5). Occhioni, P. s.n. RB 44113 (4). Okada, K.A. s.n. CEN 787 (4). Oliveira, A.A. 2706 (8). Oliveira, E. 40, 101, 1784, 4417 (8). Oliveira, F.C.A. 126, 452 (4). Oliveira, P.E.A.M. 131 (4). Onishi, E. 814 (4). Orlandi, R.P. 49 (4). Ortíz, M. 688 (5). Ortíz, R.T. 1995 (9). Paixão, I.L.S.C. 10 (4). Passareli, C.A. s.n. FUEL 6436 (5). Paula, J.F. 174 (4), 985 (8). Pena, B. 9, 454 (8). Peña, M. 191 (8). Pennington, R.T. 619 (9). Pennington, T.D. 9387 (9). Pereira Neto, M. 502 (4). Pereira, B.A.S. 118 (4), 458 (6), 1208, 1302, 2261, 2946, 3265, 3343, 3454 (4). Pereira, E. 3403 (8). Pereira-Noronha, M.R. 1314 (5), 1616 (4). Pereira-Silva, G. 5517 (4). Philcox, D. 3488 (4). Pickel, D.B. 789 (5), 3391 (4), 3480, s.n. SPF 82286 (5). Pilger, R.K.F. 243 (4). Pinheiro, M.H.O. 211 (5). Pinto, G.C. 28-86 (2). Pipoly, J.J. 11419 (8). Pirani, J.R. 298 (4), 1068 (2), in CFCR 6083, in CFCR 6810, in CFCR 11337, in CFCR 11884, in CFCR 12807, in CFCR 13073 (4). Pires, J.M. 1190a, 3637, 3999, 11906, 13885 (8), 14611 (11), 16968 (4), 17193, 17224 (5), 50355, 50783 (8). Plowman, T.C. 9034 (1). Poeppig, E.F. s.n. L 0488483 (8). Pohl, J.B.E. 248b (7), 451, s.n. BR 842306 (4). Poole, J.M. 1636, 1647, 1686 (8). Pott, A. 7001 (5). Prance, G.T. 4605 (11), 4733, 5660, 11505, 11745, 15111 (8), 19203 (4), 20573, 29833, 29996 (8). Queiroz, L.P. 2072 (4), 2489, 2873 (2), 3583 (4), 3763 (2). Quevedo 2380 (8). Quintela, M.F. 12/99 (8). Ramos, A.E. 160, 331, 361 (4), 397 (7). Ramos, J. 73 (4). Ramos, P.C.M. 325, 326 (4). Ratter, J.A. 1397, 1587 (8), 2428, 2611 (4). Rawitscher, F. s.n. SPF 85334 (5). Regnell, A.F. 67 (4). Rezende, J.M. 140 (4). Riedel, L. 191 also 56 (3), 1267 (8). Rivera, M.D. 80-500 (4). Rizzini, C.T. 923 (5), s.n. RB 112991 (4). Rizzo, J.A. 7209 (4). Rocha, Y.T. 64 (5). Rodrigues, I.A. 949 (4), 1130 (8). Rodrigues, R.S. 993 (5), 1001, 1008, 1015 (4), 1078, 1085, 1105 (5), 1109 (4), 1110, 1129 (5), 1130, 1137, 1141 (4), 1154, 1155, 1165 (5), 1167 (4), 1169, 1170, 1174 (5), 1175, 1187 (4), 1203 (5), 1207 (4), 1243 (5), 1286 (4), 1293, 1294, 1295 (3), 1315, 1340, 1350, 1353 (4), 1355 (3), 1367, 1380, 1382, 1385, 1392, 1395, 1432, 1442, 1449, 1476 (4), 1498, 1499 (10), 1563 (4), 1600 (2), 1603 (12), 1616 (8). Rodrigues, W. 7802 (8). Rojas, T. 6476 (5). Romeiro, P.J.M. 6 (5). Romero, G.A. 2099 (8). Romero, P. 12 (9). Romero, R. 3213 (5). Roque, N. 384 (3), in CFCR 14910, in CFCR 14911 (4). Rosa, N.A. 1430, 1916 (8), 4981 (4). Rosales, J. 8 (8), 414 (11). Rosário, C.S. 750 (8). Rossi, L. in CFCR 1051 (4). Roth, L. 1856 (6), 1910 (4), 1911 (4). Russel, A. 229 (5). Rutkis, E. 644 (8). s.col. RB 38476 (6), P
00312232 (4). Saddi, N. 3689 (4). Salatino, M.L.F. 60, 81, 83 (4), 85, 158 (5), 214 (4). Salino, A. 6778 (5). Sanaiotti, T.M. 224 (11). Sano, P.T in CFCR 12617 (4), in CFCR 12809 (3), in CFCR 14838 (4). Santos, E. 521 (4). Santos, J. 320 (4). Santos, J.V. 3264 (9). Santos, T.S. 2217 (2), 3492 (4), 4535 (2). Sarmento, A.C. 673 (4). Sartori, A.L.B. 27255, 28968 (5), 31365 (4). Sartori, H. 7 (5). Sato, A. s.n. SP 184735, s.n. UEC 84395 (5). Schianini, A. 382 (5). Schinini, A. 27846, 29963 (5). Schipp, W.A. 462 (9). Schomburgk, R.H. 526 (8). Schultes, R.E. 10065, 12526, 24523 (8). Schwacke, J. 4911 (8), 8658 (4). Sellow, F. s.n. BR 842321 (2), s.n. F 621389 (12), s.n. F 1540139 (5), s.n. F 1540140 (2), s.n. F 1540595 (5), s.n. K 000188700 (2), s.n. K 000500794, s.n. US 2894 (4), s.n. US 63555, s.n. US 2253985 (5). Sendulsky, T. 875, 876 (5). Sette-Silva, E.L. 717 (8). Shepherd, G.S. 3911 (3), 9428 (2). Silva, E.S. 188 (8). Silva, F.C.F. 157, 169 (4). Silva, J.A. 354, 626 (8). Silva, J.M. 1827 (5). Silva, M. 1658 (8). Silva, M.A. 3621, 3714 (4), 4203 (8). Silva, M.G. 3622 (8). Silva, N.T. 4202 (8), 57183 (4), in Jari 020 (8). Silva, S.B. 111 (4). Silva, S.J.R. 95 (11). Silva, S.S. 1 (8). Simão, S. 259 (4). Smith, L.B. 14614, 14847 (5). Soares, F.A.R. 119 (4). Sonkin, L. 124, 204 (8). Soria, N. 4196 (5). Sousa, M. 5909, 7953 (9). Souza, H.J.R. 1 (8). Souza, H.M. s.n. IAC 19548 (5). Souza, M.F.L. 106 (4). Souza, S.A.M. 959, 1209 (8). Souza, V. 353 (12), 432 (2). Souza, V.C. 7301 (5), 14196 (4), 14270a (8), 14401, 20078, 20752, 22277 (4), 22428, in CFCR 8774 (3). Splitgerber, F.L. 763 (8). Spruce, R. 921, 3310, 6022 (8). Stannard, H.B. 51812 (4). Stergios, B. 10936 (8). Steyermark, J.A. 86795 (8), 88252, 131496 (11). Sucre, D. 10524 (5). Tamashiro, J.Y. 114, 422 (4). Tamayo, F. 4026 (8). Tameirão Neto, E. 2153 (5), 3130 (4). Taxonomic Class of Univ. de Brasília 177, 203, 473, 1053 (4). ter Steege, H. 318 (8). Teunissen, L.B.B. 15444 (8). Thomas, W.W. 4875 (3), 6111 (2). Tiritan, O. 269 (4), 274 (5), 475 (4). Torezan, J.M. 735 (5). Torres, R. 15, 6006 (9). Tosta, C.D. 33 (4). Tozzi, A.M.G.A. 28703, 94-275 (5). Trigos, C. 3340 (9). Uhlmann, A. 65 (5). Ule, E. $6086(8), 7156,7433$ (10), 7600 (8), 7774, 8152, 8153 (11), 8865 (8). Válio, J.M. 340 (5). Valle, M.P. 17 (4). Vasconcelos, R.T.P. 455 (8). Vecchi, O. 178, 1910, s.n. RB 25411 (5), s.n. SP 1635 (4). Viana, B.F. 4 (2). Vianna, M.C. 1360 (12). Vieira, R.F. 482 (4). Vilhena, R. 169, 299 (8). Vinha, P. 958 (2). Violatti, L.G. 32 (4). Wagner, H.L. in CFCR 6065 (4), in CFCR 9470 (3). Walter, B.M.T. 2074, 2285, 2728, 2928, 3956 (4). Warming, E. s.n. UC 478568 (4). Wasum, R. 7583 (4), 8116 (2). Williams, L. 15459, 15899 (8). Windisch, P.G. 7097 (4). Wit, H.C.D. s.n. L 0488491 (9). Woolston, A.L. 908, 1152 (5). Wurdack, J.J. 42799, 43237 (8). Zanderij, I. 176, 2688, 3351 (8). Zardini, E. 10422 (5). Zaruchi, J.L. 1382, 3215, 3220 (8). Zehnter 408 (4). 